\title{
Article \\ Cell-Penetrating Delivery of Nitric Oxide by Biocompatible Dinitrosyl Iron Complex and Its Dermato-Physiological Implications
}

\author{
Yu-Chieh Chen ${ }^{1,+}+\mathbb{D}$, Yi-Hong Chen ${ }^{2,+}{ }^{(\mathbb{D}}$, Han Chiu ${ }^{2}$, Yi-Hsuan Ko ${ }^{1}$, Ruei-Ting Wang ${ }^{3}$, Wei-Ping Wang ${ }^{3}$, \\ Yung-Jen Chuang ${ }^{1}$, Chieh-Cheng Huang ${ }^{2, * \mathbb{D}}$ and Tsai-Te Lu ${ }^{2, *(\mathbb{D})}$ \\ 1 Department of Medical Science \& Institute of Bioinformatics and Structural Biology, National Tsing Hua \\ University, Hsinchu 30013, Taiwan; jeremy80808@gmail.com (Y.-C.C.); 0953665406irisko@gmail.com (Y.-H.K.); \\ yjchuang@life.nthu.edu.tw (Y.-J.C.) \\ 2 Institute of Biomedical Engineering, National Tsing Hua University, Hsinchu 30013, Taiwan; \\ chenyh@gapp.nthu.edu.tw (Y.-H.C.); chiuhan911@gmail.com (H.C.) \\ 3 CHLITINA Research and Development Center, CHLITINA Holding Ltd., Taipei 10073, Taiwan; \\ mia.wang@tw.chlitina.com (R.-T.W.); wpw.wang@tw.chlitina.com (W.-P.W.) \\ * Correspondence: chiehcheng@mx.nthu.edu.tw (C.-C.H.); ttlu@mx.nthu.edu.tw (T.-T.L.) \\ + These authors contributed equally to this work.
}

\section{check for} updates

Citation: Chen, Y.-C.; Chen, Y.-H.; Chiu, H.; Ko, Y.-H.; Wang, R.-T.; Wang, W.-P.; Chuang, Y.-J.;

Huang, C.-C.; Lu, T.-T.

Cell-Penetrating Delivery of Nitric Oxide by Biocompatible Dinitrosyl Iron Complex and Its

Dermato-Physiological Implications. Int. J. Mol. Sci. 2021, 22, 10101.

https://doi.org/10.3390/ijms221810101

Academic Editor: Anatoly F. Vanin

Received: 23 August 2021

Accepted: 16 September 2021

Published: 18 September 2021

Publisher's Note: MDPI stays neutral with regard to jurisdictional claims in published maps and institutional affiliations.

Copyright: (c) 2021 by the authors. Licensee MDPI, Basel, Switzerland. This article is an open access article distributed under the terms and conditions of the Creative Commons Attribution (CC BY) license (https:/ / creativecommons.org/licenses/by/ $4.0 /)$.
Abstract: After the discovery of endogenous dinitrosyl iron complexes (DNICs) as a potential biological equivalent of nitric oxide $(\mathrm{NO})$, bioinorganic engineering of $\left[\mathrm{Fe}(\mathrm{NO})_{2}\right]$ unit has emerged to develop biomimetic DNICs $\left[(\mathrm{NO})_{2} \mathrm{Fe}(\mathrm{L})_{2}\right]$ as a chemical biology tool for controlled delivery of NO. For example, water-soluble DNIC $\left[\mathrm{Fe}_{2}\left(\mu-\mathrm{SCH}_{2} \mathrm{CH}_{2} \mathrm{OH}\right)_{2}(\mathrm{NO})_{4}\right]$ (DNIC-1) was explored for oral delivery of $\mathrm{NO}$ to the brain and for the activation of hippocampal neurogenesis. However, the kinetics and mechanism for cellular uptake and intracellular release of NO, as well as the biocompatibility of synthetic DNICs, remain elusive. Prompted by the potential application of NO to dermatophysiological regulations, in this study, cellular uptake and intracellular delivery of $\mathrm{DNIC}\left[\mathrm{Fe}_{2}(\mu-\right.$ $\left.\mathrm{SCH}_{2} \mathrm{CH}_{2} \mathrm{COOH}\right)_{2}(\mathrm{NO})_{4}$ ] (DNIC-2) and its regulatory effect/biocompatibility toward epidermal cells were investigated. Upon the treatment of DNIC-2 to human fibroblast cells, cellular uptake of DNIC-2 followed by transformation into protein-bound DNICs occur to trigger the intracellular release of NO with a half-life of $1.8 \pm 0.2 \mathrm{~h}$. As opposed to the burst release of extracellular NO from diethylamine NONOate (DEANO), the cell-penetrating nature of DNIC-2 rationalizes its overwhelming efficacy for intracellular delivery of NO. Moreover, NO-delivery DNIC-2 can regulate cell proliferation, accelerate wound healing, and enhance the deposition of collagen in human fibroblast cells. Based on the in vitro and in vivo biocompatibility evaluation, biocompatible DNIC-2 holds the potential to be a novel active ingredient for skincare products.

Keywords: nitric oxide; dinitrosyl iron complex; controlled delivery; wound healing; collagen deposition

\section{Introduction}

Based on the distinctive electron paramagnetic resonance $(\mathrm{EPR})$ signal at $\mathrm{g} \approx 2.03$ observed in the baker's yeast cells (S. cerevisiae), biosynthesis of dinitrosyl iron complexes (DNICs) was first discovered by Prof. Vanin in 1964 [1-4]. Later, continued investigations explored tetrahedral DNICs $\left[(\mathrm{NO})_{2} \mathrm{Fe}(\mathrm{L})_{2}\right]$ as a natural and ubiquitous cofactor generated upon the interaction of nitric oxide (NO) with non-heme [Fe-S] proteins and cellular labile iron pools [5-18]. Despite the identification of $\mathrm{NO}$ as an endothelium-derived relaxing factor (EDRF) [19,20], DNICs in a low-molecular-weight or protein-bound form were proposed as a "working form" of $\mathrm{NO}$ under physiological conditions [21,22]. As a potential biological equivalent of $\mathrm{NO}$, bioinorganic engineering of $\left[\mathrm{Fe}(\mathrm{NO})_{2}\right]$ unit has emerged to develop biomimetic DNICs as a chemical biology tool for controlled delivery of NO and translation of NO-related functions into biomedical applications [23,24]. In particular, 
biomimetic DNICs and their conjugates with drug delivery systems were explored for antiaging/anti-inflammatory/anti-viral effect, anti-cancer/anti-hypertensive therapy, diabetic angiogenesis/wound healing, penile erection, and treatment of mild cognitive impairment and neurodegenerative diseases [25-35]. In particular, phase I and phase II clinical trials of glutathione-bound DNICs $\left[\mathrm{Fe}_{2}(\mu \text {-glutathione })_{2}(\mathrm{NO})_{4}\right]$, a commercial medical product with the pharmacological name Oxacom ${ }^{\circledR}$, was reported for application as a clinical medicine against hypertension [30,31].

Inspired by the potential of biomimetic DNICs for biomedical applications, synthetic advances in the development of structure-characterized and water-soluble DNICs enabled the study of trafficking and NO-delivery reactivity of DNICs under simulated physiological conditions, in vitro, and in vivo [26,28,36-39]. Water-soluble DNIC $\left[\mathrm{Fe}_{2}(\mu-\right.$ $\left.\left.\mathrm{SCH}_{2} \mathrm{CH}_{2} \mathrm{OH}\right)_{2}(\mathrm{NO})_{4}\right]$ (DNIC-1) displays an $\mathrm{O}_{2}$-triggered degradation mechanism for the release of nitric oxide, ferric ion, and disulfide with a half-life of $27.4 \mathrm{~h}$ and $15.5 \mathrm{~h}$ in an aqueous buffer solution ( $\mathrm{pH}=7.0$ or 7.4$)$ at $25^{\circ} \mathrm{C}$ and $37^{\circ} \mathrm{C}$, respectively $[25,32,34]$. In simulated gastric fluid (SGFsp, $\mathrm{pH} 1.2$ ), a shortened half-life of $0.4 \mathrm{~h}$ indicates the acid-sensitive nature of DNIC-1. To mimic the systemic circulation system, the addition of serum albumin initiated the coordination of Cys-34 toward DNIC-1 leading to the partial formation of albumin-bound DNIC, which features an accelerated release of NO with a half-life of $3.5 \mathrm{~h}$ in phosphate-buffered saline (PBS) [34,39-42]. Regarding the NO-release reactivity of synthetic DNICs, their capability for the elevation of intracellular NO levels, activation of the NO-soluble guanylyl cyclase (sGC)-cyclic guanosine monophosphate (cGMP) pathway (NO-sGC-cGMP pathway), and regulation of cGMP-dependent cell proliferation was also reported $[32,34,39,43]$. Moreover, the discovery of multidrug-resistance-associated protein 1 as a transporter for the efflux of glutathione-bound DNICs from the cells may establish a mechanism for transcellular trafficking of DNIC after its uptake by cells [44-46]. Of importance, the endogenous conjugation of DNIC-1 with gastrointestinal mucin and serum albumin in a reversible manner was reported to facilitate oral delivery of the $\left[\mathrm{Fe}(\mathrm{NO})_{2}\right]$ unit to the brain across the intestinal epithelial and blood-brain barriers, respectively [34]. Despite the investigations put forward, kinetics for in vitro NO-release reactivity, the mechanism for cellular uptake and intracellular release of $\mathrm{NO}$, and the biocompatibility of synthetic DNICs remain elusive.

Prompted by the potential application of $\mathrm{NO}$ to dermato-physiological regulations [47-50], herein, the mechanism for intracellular delivery of DNIC $\left[\mathrm{Fe}_{2}\left(\mu-\mathrm{SCH}_{2} \mathrm{CH}_{2} \mathrm{COOH}\right)_{2}(\mathrm{NO})_{4}\right]$ (DNIC-2) and its regulatory effect/biocompatibility toward epidermal cells were investigated (Chart 1). Upon the treatment of DNIC-2 to human fibroblast cells, cellular uptake of DNIC-2 and transformation into protein-bound DNICs occur to trigger the intracellular release of $\mathrm{NO}$ with a half-life of $1.8 \pm 0.2 \mathrm{~h}$. As opposed to the burst release of extracellular NO from diethylamine NONOate (DEANO), the cell-penetrating nature of DNIC-2 rationalizes its overwhelming efficacy for intracellular delivery of NO. Despite the absent regulation of pigmentation of B16-F10 melanoma cells, notable effects on cell proliferation, accelerated wound healing, and the enhanced deposition of collagen were observed upon treatment of DNIC-2 to human fibroblast cells. Based on the biocompatibility evaluation using a 2-D culture of fibroblast/melanocyte/keratinocyte cells, 3-D culture of reconstructed human epidermis and human cornea-like epithelium models, and zebrafish embryo, DNIC-2 holds the potential for further development as a novel active ingredient for skincare products.

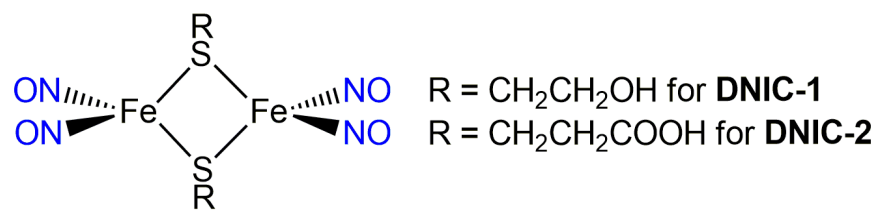

Chart 1. Structure of DNICs $\left[\mathrm{Fe}_{2}\left(\mu-\mathrm{SCH}_{2} \mathrm{CH}_{2} \mathrm{OH}\right)_{2}(\mathrm{NO})_{4}\right]$ (DNIC-1) and $\left[\mathrm{Fe}_{2}\left(\mu-\mathrm{SCH}_{2} \mathrm{CH}_{2} \mathrm{COOH}\right)_{2}(\mathrm{NO})_{4}\right]$ (DNIC-2). 


\section{Results and Discussion}

2.1. Cellular Uptake of Dinitrosyl Iron Complex (DNIC) $\left[\mathrm{Fe}_{2}\left(\mu-\mathrm{SCH}_{2} \mathrm{CH}_{2} \mathrm{COOH}\right)_{2}(\mathrm{NO})_{4}\right]$ (DNIC-2) and Intracellular Release of Nitric Oxide (NO)

\subsubsection{Kinetic Study of NO-Release Reactivity for DNIC-2}

Kinetics and efficacy for the release of NO from DNIC-2 in a cell culturing medium, the minimum essential medium (MEM), were investigated to project on the in vitro study discussed below. Similar to the reported DNIC [ $\left.\mathrm{Fe}_{2}\left(\mu-\mathrm{SCH}_{2} \mathrm{CH}_{2} \mathrm{OH}\right)_{2}(\mathrm{NO})_{4}\right]$ (DNIC-1) [25,34], DNIC-2 exhibits a steady and aerobic decomposition with a half-life of $4.2 \pm 0.6 / 3.5 \pm 0.3 \mathrm{~h}$ in MEM with/without the presence of $10 \%$ fetal bovine serum (FBS) (Figure 1a-d). Moreover, this aerobic degradation of DNIC-2 results in a concomitant release of $\sim 4$ equiv. of NO based on the total nitrite/nitrate assay (Figure 1e). In addition, the aerobic decomposition of DNIC-2 and release of NO was also validated using an NO-specific fluorescence probe, 4-amino-5-methylamino-2' ${ }^{\prime} 7^{\prime}$-difluorofluorescein diacetate (DAF-FM), whereas the NO donor diethylamine NONOate (DEANO) was used for comparison. Regarding the stoichiometry of released $\mathrm{NO}(\approx 4$ equiv. for DNIC-2 and 1.5 equiv. for DEANO), reactions of DAF-FM with $50 \mu \mathrm{M}$ of DNIC-2 and $133 \mu \mathrm{M}$ of DEANO, respectively, were further performed. In comparison with DAF-FM only, both DNIC-2 and DEANO trigger a time-dependent and significant increase of fluorescence intensity (Figure 1f). Relevant to the reported DNIC-1 [34], presumably, $\mathrm{O}_{2}$-induced oxidation of the $\left[\mathrm{Fe}(\mu-\mathrm{SR})_{2} \mathrm{Fe}\right]$ core in DNIC-2 weakens the Fe-to-NO $\pi$-backbonding interaction and initiates the release of $\mathrm{NO}$ as probed by DAF-FM under aerobic conditions [51]. In the absence of an NO-responsive target (i.e., DAF-FM), the subsequent oxidation of released NO results in the formation of nitrite/nitrate.
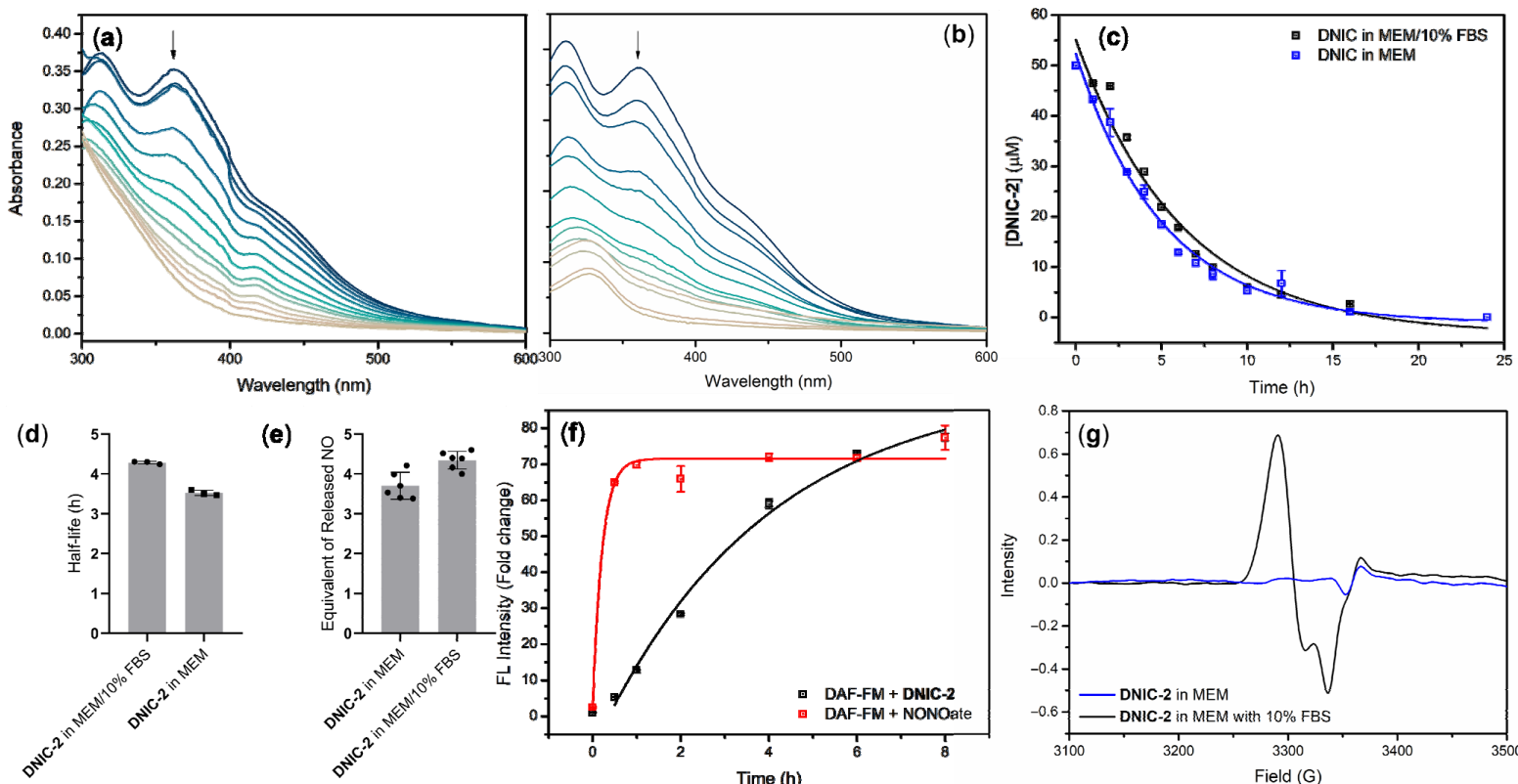

(e)
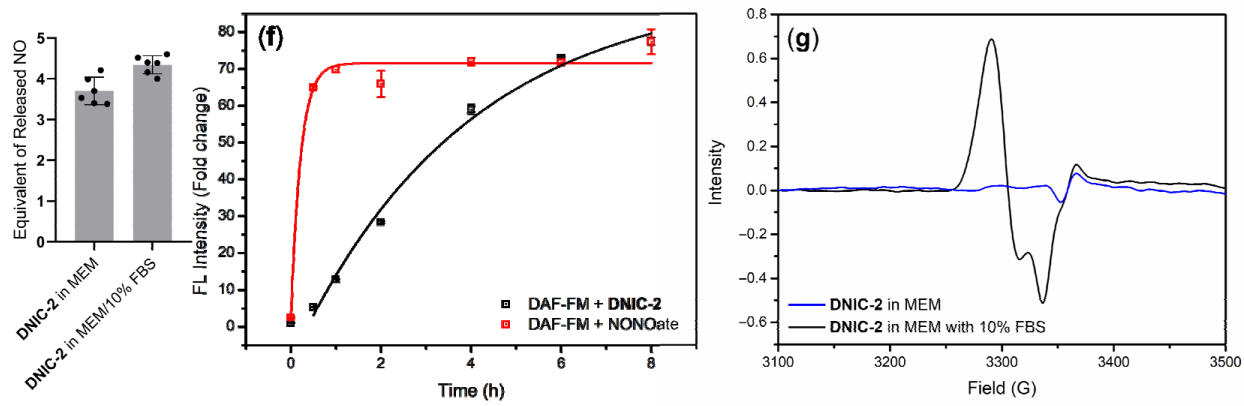

Figure 1. Kinetics and efficacy study of NO-release reactivity of $\left[\mathrm{Fe}_{2}\left(\mu-\mathrm{SCH}_{2} \mathrm{CH}_{2} \mathrm{COOH}\right)_{2}(\mathrm{NO})_{4}\right](\mathrm{DNIC}-2)$. Timedependent change of UV-vis spectra for DNIC-2 in MEM (a) with and (b) without the presence of $10 \%$ FBS. The arrows indicate the time-dependent change of the UV-vis spectra. (c) Decompositions of DNIC-2 in MEM with (black) and without (blue) the presence of $10 \%$ FBS, respectively, which were fitted to pseudo-first-order kinetics. Data show the mean \pm SD from three independent experiments. (d) Half-life for decomposition of DNIC-2 in MEM with or without the presence of $10 \%$ FBS at $37^{\circ} \mathrm{C}$. Data represent the mean $\pm \mathrm{SD}(n=3)$. (e) Equivalent of released nitric oxide during degradation of DNIC-2. The data are the mean values \pm SD pooled from six independent experiments. (f) Time-dependent change of relative fluorescence intensity of NO-specific probe DAF-FM (excitation at $495 \mathrm{~nm}$ and emission at $535 \mathrm{~nm}$ ) with the treatment of $50 \mu \mathrm{M}$ of DNIC-2 (black) or $133 \mu \mathrm{M}$ of NONOate (red) in MEM with 10\% FBS, which were fitted to pseudo-first-order kinetics. Data show the mean \pm SD from three independent experiments. (g) EPR spectra for DNIC-2 in MEM with (black) and without (blue) the presence of $10 \%$ FBS, respectively. 
With regard to the reported interconversion between low-molecular-weight and proteinbound DNICs [7,34,52,53], the formation of protein-bound DNIC derived from DNIC-2 in MEM with/without the presence of $10 \%$ FBS was further explored. As opposed to the EPR silence displayed by DNIC-2 in MEM, the addition of 10\% FBS results in the assembly of protein-bound DNIC based on the formation of a rhombic EPR signal at $\mathrm{g}=2.043,2.036$, and 2.015 (Figure 1g). Using DNIC [PPN][(NO) $\left.{ }_{2} \mathrm{Fe}\left(\mathrm{S}_{5}\right)\right]$ (PPN = bis(triphenylphosphine)iminium, $\mathrm{S}_{5}=$ pentasulfide) as a standard, spin quantitation of this protein-bound DNIC determines a 1.5\%-conversion of low-molecular-weight DNIC-2 into the protein-bound form (Figure S1). In comparison with other protein-bound and biomimetic DNICs [(NO) $\left.{ }_{2} \mathrm{Fe}(\mathrm{SR})(\mathrm{L})\right]^{-}[54]$, serum albumin is proposed to facilitate this minor formation of protein-bound DNIC upon incubation of DNIC-2 in MEM with the presence of $10 \%$ FBS, in which the concentration of serum albumin is $2.1 \mathrm{mg} / \mathrm{mL}$ (Tables S1 and S2). This minor formation of protein-bound DNIC, moreover, rationalizes the comparable half-life and efficacy for the release of NO from DNIC-2 in MEM with or without the presence of 10\% FBS discussed above. Considering $10 \% \mathrm{FBS}$ as an essential ingredient, the in vitro study described in the following sections was performed in MEM with the presence of $10 \%$ FBS.

2.1.2. Cellular Uptake of DNIC-2 and Intracellular Release of NO in CCD-966SK Human Skin Fibroblast Cells

As shown in Figure 2a, DNIC-2 exhibits an $\mathrm{IC}_{50}$ value of $92.3 \mu \mathrm{M}$ toward CCD-966SK human skin fibroblast cells based on the CCK-8 assay. Accordingly, $50 \mu \mathrm{M}$ of DNIC-2 was further treated to CCD-966SK cells in the attempt to explore the cellular uptake of DNIC-2 followed by the intracellular release of NO. Upon the addition of $50 \mu \mathrm{M}$ of DNIC-2 to CCD-966SK cells, the time-dependent formation of EPR signal at $g=2.041,2.034$, and 2.015 indicates the cellular uptake of DNIC-2 followed by intracellular transformation of DNIC-2 into protein-bound DNICs, of which the level starts to decay after treatment of DNIC-2 for $1 \mathrm{~h}$ (Figure 2b,c). Through the sequential incubation of CCD-966SK cells with an NO-specific probe DAF-FM and DNIC-2, the elevated generation of intracellular fluorescence signal demonstrates the successful delivery of NO into CCD-966SK cells by DNIC-2 (Figure 2d). Moreover, a 22-fold increase of intracellular fluorescence intensity in a steady manner reflects that DNIC-2 features a half-life of $1.8 \pm 0.2 \mathrm{~h}$ for cell-penetrating delivery of NO in CCD-966SK cells (Figure 2e). This contrasts with the instantaneous formation of a maximum 10-fold increase of fluorescence intensity observed after treatment of DEANO, which features a half-life of $0.2 \pm 0.1 \mathrm{~h}$ (Figure 2d,e). That is, DNIC-2 features a steady and more effective cell-penetrating delivery of NO overwhelming the DEANO. Presumably, cellular uptake of DNIC-2 and its transformation into protein-bound DNICs followed by the intracellular release of NO may rationalize its overwhelming efficacy for the cell-penetrating delivery of NO. Considering that the biological targets responsive for NO-related physiology (i.e., soluble guanylyl cyclase (sGC)) are located in the intracellular compartment, the potential of effective NO-delivery DNIC-2 prompts our in vitro investigations on its dermato-physiological applications.

\subsection{NO-Delivery DNIC-2 Promoted the Proliferation, Migration and Collagen Deposition of Skin Fibroblasts}

To evaluate the potential of the developed NO donor for dermatological application, we first investigated the effects of low-dose DNIC-2 on the behaviors of CCD-966SK cells. After a 48-h incubation, a higher cell density was observed in the groups that received the treatment of DNIC-2 than that of the untreated control (Figure 3a). Furthermore, the fibroblasts that were treated with $100 \mathrm{pM}, 10 \mathrm{nM}$, and $1 \mu \mathrm{M}$ DNIC-2 showed $18.1 \pm 4.1 \%, 13.5 \pm 4.0 \%$, and $12.2 \pm 2.4 \%$ increases in cell density, respectively $(p<0.001$; Figure $3 b)$, suggesting that DNIC-2 could efficiently promote fibroblast proliferation. Although the effects of NO on modulating skin fibroblast proliferation were reportedly controversial $[47-49,55,56]$, most studies employed short-term NO donors that evolve NO for only several minutes. In the present study, however, the developed DNIC-2 with a half-life of $\sim 4 \mathrm{~h}$ for the steady release of NO, thus, features a distinct impact on fibroblast proliferation. 
(a)
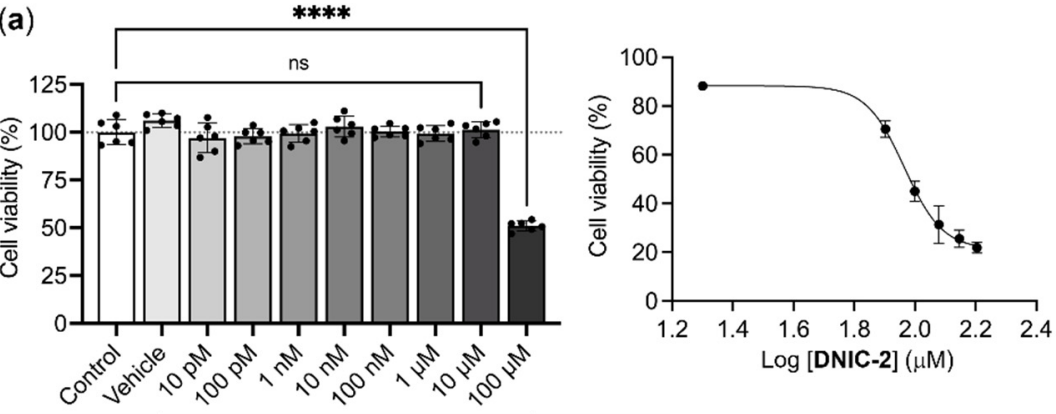

[DNIC-2]
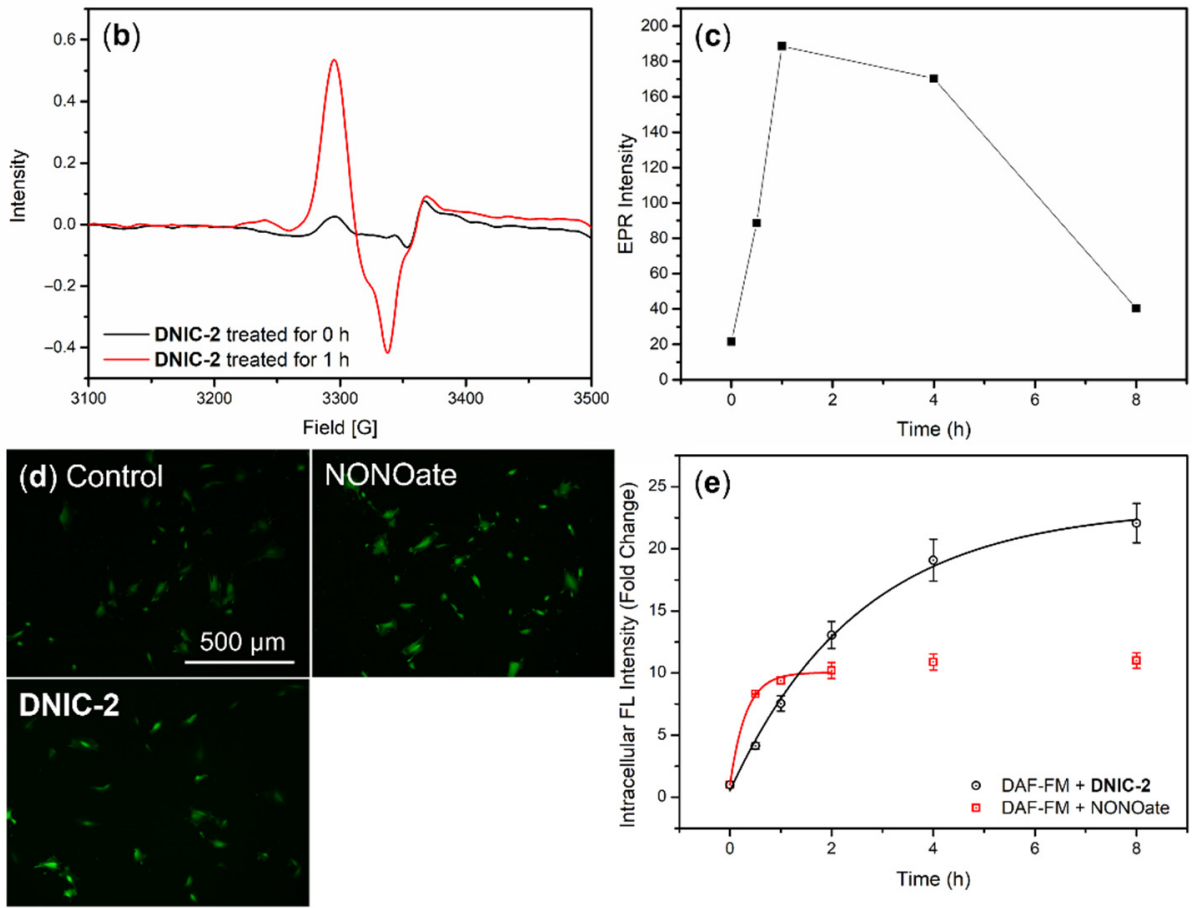

Figure 2. Cellular uptake of DNIC-2 and intracellular release of nitric oxide in human skin fibroblast (CCD-966SK) cells. (a) Cell viability assay of the human skin fibroblast (CCD-966SK) cells treated with different concentrations of DNIC-2 for $24 \mathrm{~h}^{* * * *} p<0.001$ compared to the group without treatment of DNIC-2. (b) Representative EPR spectra for CCD-966SK cells treated with $50 \mu \mathrm{M}$ of DNIC-2 for $0 \mathrm{~h}$ (black) and $1 \mathrm{~h}$ (red). (c) Formation and decay of protein-bound DNIC in CCD-966SK cells after treatment of $50 \mu \mathrm{M}$ of DNIC-2 for 0, 0.5, 1, 4, and $8 \mathrm{~h}$. (d) Fluorescence images of CCD-966SK cells treated with DAF-FM $(10 \mu \mathrm{M})$ for $1 \mathrm{~h}$, with DAF-FM $(10 \mu \mathrm{M})$ and DNIC-2 $(50 \mu \mathrm{M})$ for $4 \mathrm{~h}$, and with DAF-FM $(10 \mu \mathrm{M})$ and NONOate $(133 \mu \mathrm{M})$ for $1 \mathrm{~h}$, respectively. (e) Time-dependent change of fluorescence intensity of CCD-966SK cells treated with $10 \mu \mathrm{M}$ of DAF-FM and $50 \mu \mathrm{M}$ of DNIC-2 (black) or with $10 \mu \mathrm{M}$ of DAF-FM and $133 \mu \mathrm{M}$ of NONOate (red) for $0,0.5,1,2,4$, and $8 \mathrm{~h}$, which were fitted to pseudo-first-order kinetics. Data show the mean \pm SD from three independent experiments.

The potential of exogenously administered $\mathrm{NO}$ in accelerating fibroblast migration, a key step involved in skin wound healing [57], has been well-documented [50,55]. Herein, an in vitro scratch wound healing assay was conducted to analyze the capacity of DNIC-2 in promoting fibroblast migration. After creating a wound gap on a confluent culture using a sterilized P200 tip, the CCD-966SK cells were treated with the media that contained DNIC-2 before being incubated for $24 \mathrm{~h}$. As revealed in Figure $4 \mathrm{a}, \mathrm{b}$, more cells were observed in the gap area in DNIC-2-treated groups than that of the untreated control $(p<0.05)$, indicating the capacity of DNIC-2 in promoting fibroblast migration. 
(a)
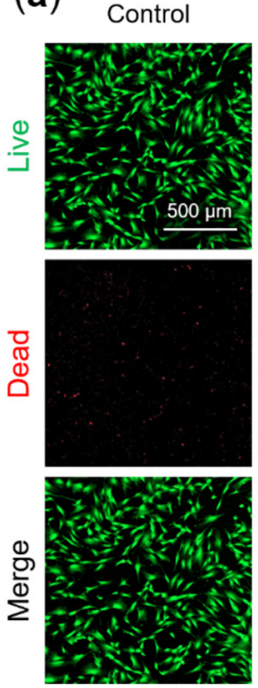
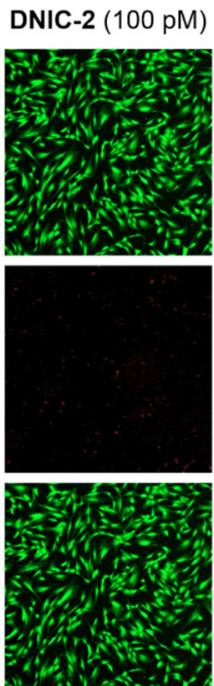
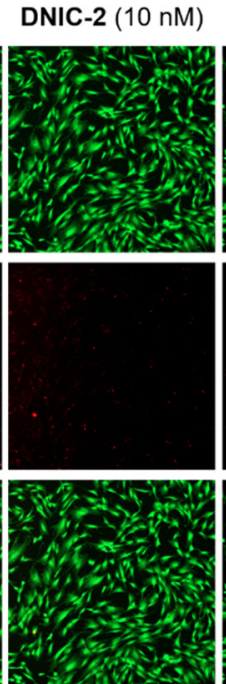

DNIC-2 $(1 \mu \mathrm{M})$
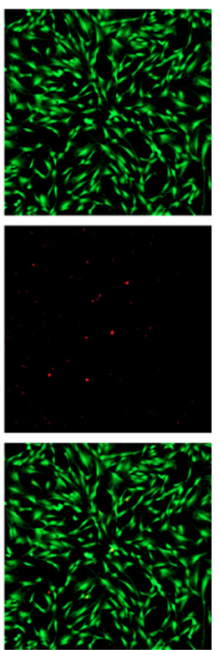

(b)

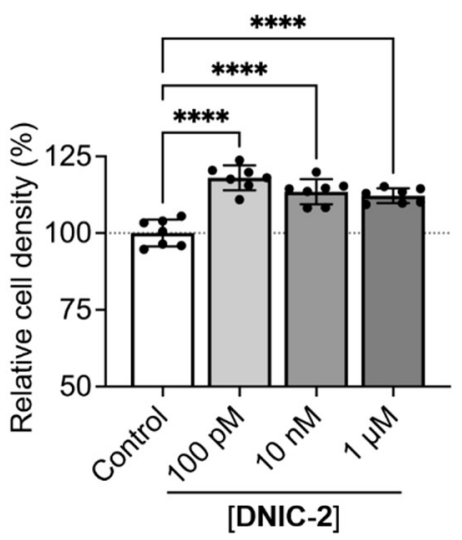

Figure 3. Low-dose DNIC-2 promotes the proliferation of human skin fibroblasts. (a) Representative live/dead staining images of DNIC-2-treated CCD-966SK cells and (b) their corresponding cell densities determined by counting the number of DAPI stained nuclei $(n=7)$. The data are presented as mean \pm SD. ${ }^{* * * *} p<0.001$.

(a)
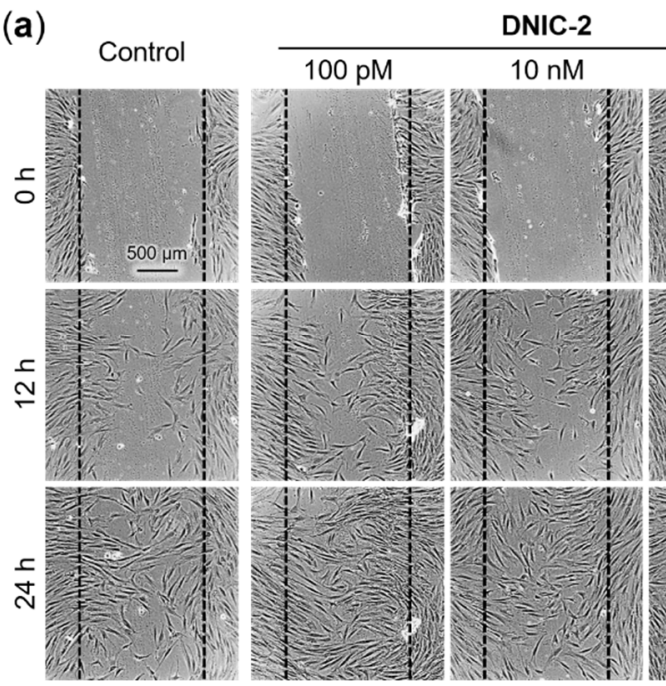

DNIC-2
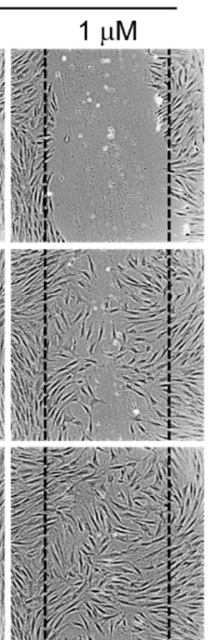

(b)
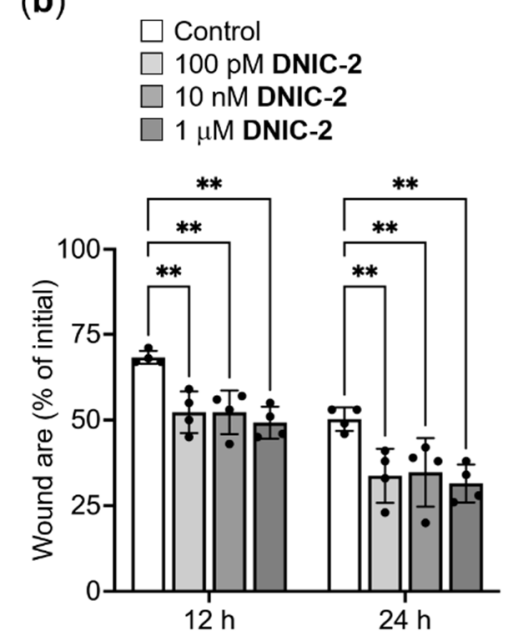

Figure 4. Low-dose DNIC-2 accelerates the migration of human skin fibroblasts. (a) Representative phase-contrast photomicrographs of DNIC-2-treated CCD-966SK cells in a scratch wound healing assay and $(\mathbf{b})$ their corresponding wound area $(n=4)$. The data are presented as mean \pm SD. ${ }^{* *} p<0.05$.

Another important physiological function of NO is to modulate the collagen deposition behavior of skin fibroblasts [47-49]. Therefore, NO donors hold great promise for various dermatological applications or to act as cosmeceuticals. Herein, to evaluate its capacity to promote collagen deposition, the administration of DNIC-2 to CCD-966SK cells was performed daily for seven consecutive days. The secreted collagen was detected by staining with Sirius Red that can bind the fibrillar collagens. According to the results in Figure 5a, the fibroblast cultures that received $10 \mathrm{nM}$ or $1 \mu \mathrm{M}$ DNIC-2 daily exhibited much denser staining than that of the untreated control. The Sirius Red dye was then extracted followed by quantification using a spectrophotometer. The obtained data further confirmed the increased collagen content in DNIC-2-treated groups $(p<0.05$; Figure 5b), a clear indication of DNIC-2 in promoting fibroblast collagen deposition. As NO has been identified as a critical mediator for controlling skin collagen accumulation [58], it is no surprise that direct administration of DNIC-2, which can release NO for a prolonged duration, 
can achieve enhanced collagen deposition. Collectively, our results clearly demonstrated that DNIC-2 could efficiently promote the proliferation, migration, and collagen deposition of skin fibroblast, thus being a promising agent for dermatological applications.

(a)

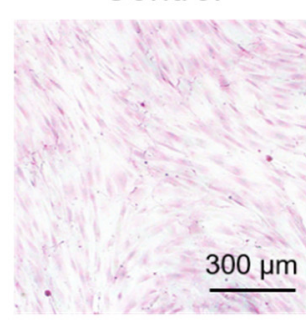

DNIC-2 (10 nM)
DNIC-2 (100 pM)

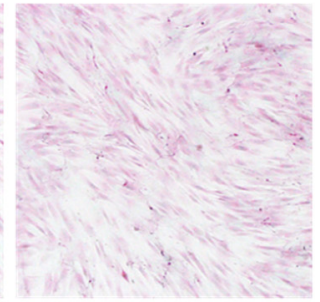

DNIC-2 $(1 \mu \mathrm{M})$

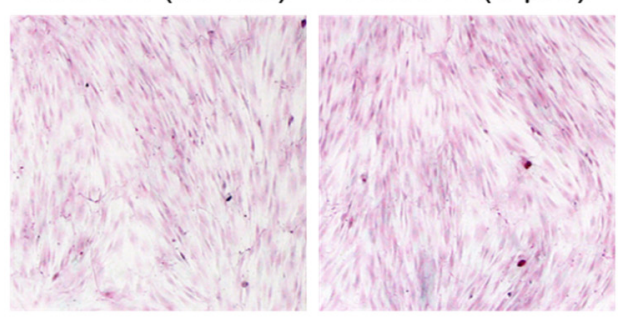

(b)

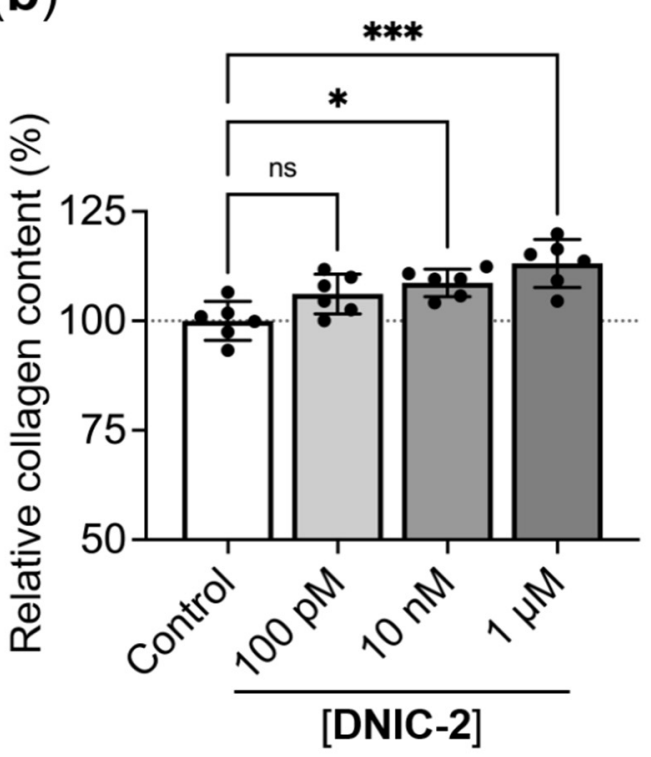

Figure 5. Low-dose DNIC-2 enhances the collagen deposition of human skin fibroblasts. (a) Representative Sirius redstained CCD-966SK cells that received treatments of various concentrations of DNIC-2 and were incubated for seven days. (b) The corresponding collagen contents quantified by extracting the dye and measuring optical density at $540 \mathrm{~nm}(n=6)$. The data are presented as mean $\pm \mathrm{SD} .{ }^{*} p<0.05 ;{ }^{* * *} p<0.005 ;$ ns, not significant.

\subsection{NO-Delivery DNIC-2 Had No Effects on the Pigmentation of Melanocytes}

By upregulating the expression level and activity of the key enzyme tyrosinase, NO has been reported as an essential signaling molecule involved in melanogenesis, a process that results in melanin biosynthesis and skin pigmentation [59,60]. To assess the effect of DNIC-2 on pigment formation, murine B16-F10 melanoma cells that received $\alpha$-melanocyte-stimulating hormone ( $\alpha$-MSH) induction were used as a model and treated with the developed NO-donor DNIC-2. Arbutin (the common whitening agent) was used as a control. After a 48-h incubation, the cell lysate and culture medium were collected for analyzing the intracellular and extracellular melanin content, respectively.

As revealed in Figure 6a,b, the melanin content in B16-F10 cells and the grown medium was increased after stimulating with $\alpha-\mathrm{MSH}$, while arbutin treatment effectively inhibited the $\alpha$-MSH-induced melanin synthesis. In all the DNIC-2-treated groups, however, changes in the level of melanin content were insignificant. We next analyzed the tyrosinase activity of the cell lysate. As shown in Figure 6c, cell lysate harvested from the DNIC-2-treated groups exhibited a similar tyrosinase activity compared to that of $\alpha$-MSH-stimulated cells. The aforementioned data demonstrated that the developed NO-delivery DNIC-2 could neither promote nor inhibit the melanogenesis of B16-F10 cells.

\subsection{Biocompatibility Evaluation of DNIC-2}

\subsubsection{In Vitro Evaluation of Biocompatibility of DNIC-2}

Inspired by the regulatory effect of NO-delivery DNIC-2 on human fibroblast cells, a biocompatibility evaluation of DNIC-2 was further performed in the attempt to validate its potential as a novel active ingredient for skincare products. In addition to an $\mathrm{IC}_{50}$ value of $92.3 \mu \mathrm{M}$ toward CCD-966SK human skin fibroblast cells, DNIC-2 features an $\mathrm{IC}_{50}$ value of $222.5 \mu \mathrm{M}$ and $350.2 \mu \mathrm{M}$ toward mouse skin melanoma and human skin keratinocyte cells, respectively (Figure 7a,b). Based on the OECD TG 439 Skin Irritation Test and OECD 
TG 492 Eye Irritation Test, absent toxicity of 50- $\mu$ M DNIC-2 toward 3-D cell culture of the reconstructed human epidermis $(\mathrm{RhE})$ and reconstructed human cornea-like epithelium models supports DNIC-2 as a biocompatible and effective NO-delivery reagent (Figure 7c,d).

(a)

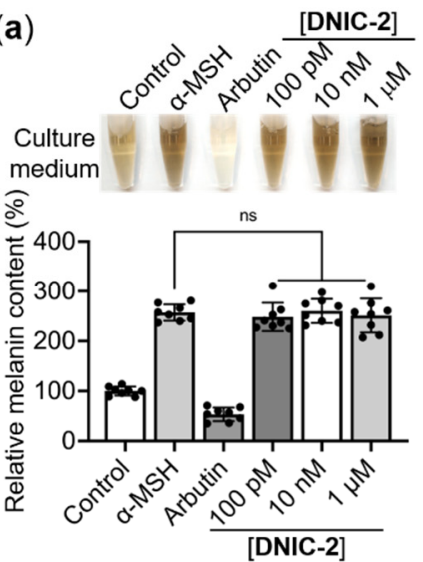

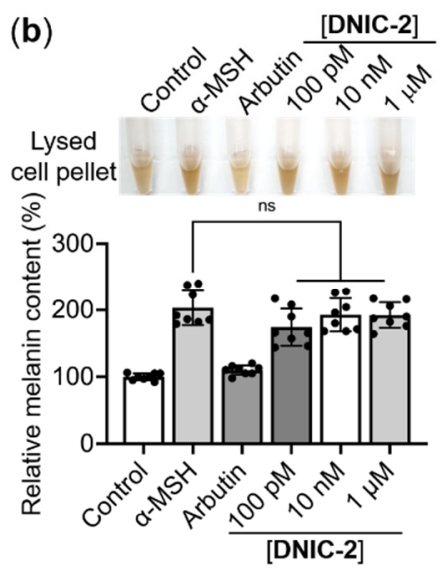

Figure 6. NO-delivery DNIC-2 does not promote pigmentation of B16-F10 melanoma cells. Representative photos and their corresponding melanin contents of (a) the culture media and (b) the $\mathrm{NaOH}-$ lysed cell pellets of B16-F10 melanoma cells exposed to $\alpha$-MSH in the presence of DNIC-2 $(n=8)$. (c) Effects of DNIC-2 on cellular tyrosinase activity $(n=8)$. The data are presented as mean \pm SD. ns, not significant.
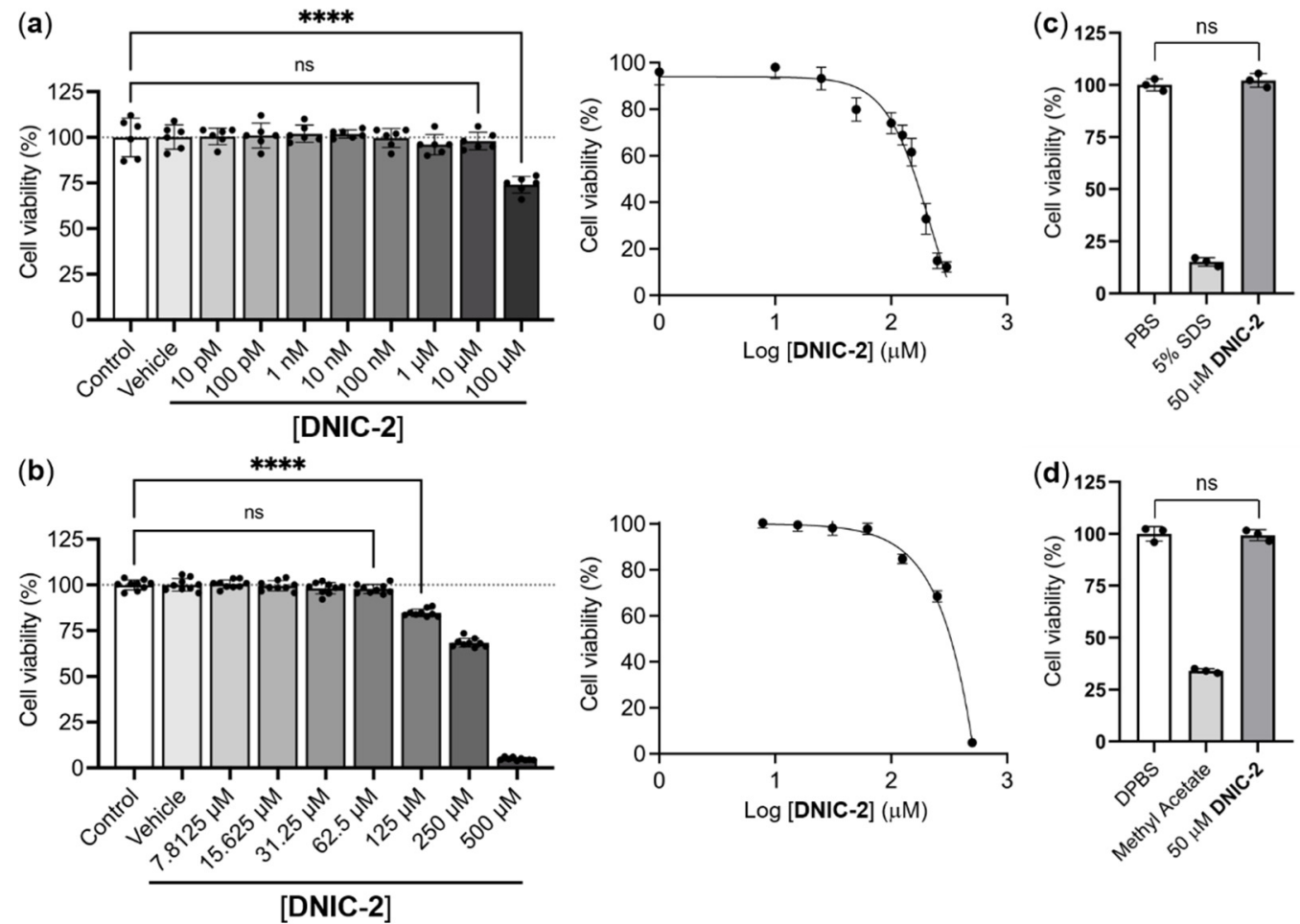

Figure 7. Cell viability assay of the (a) mouse skin melanoma (B16-F10) and (b) human skin keratinocyte cells (HaCaT) cells, respectively, treated with different concentrations of DNIC-2 for $24 \mathrm{~h}$ **** $p<0.001$ compared to the group without treatment of DNIC-2. (c) Cell viability assay of the reconstructed human epidermis (RhE) model treated with PBS, 5\% SDS, and $50 \mu \mathrm{M}$ of DNIC-2, respectively. (d) Cell viability assay of the reconstructed human cornea-like epithelium model treated with DPBS, methyl acetate, and $50 \mu \mathrm{M}$ of DNIC-2, respectively. 


\subsubsection{Biocompatibility Evaluation of DNIC-2 in Zebrafish Embryo}

To evaluate the biocompatibility of DNIC-2, zebrafish embryos were exposed to different concentrations of DNIC-2 until $96 \mathrm{~h}$ post-fertilization (hpf), whereas a parallel study of FDA-approved sodium nitroprusside (SNP) was also performed (Figure 8a). The survival rate for the control, DNIC-2-treated, and SNP-treated groups showed no significant difference (Figure 8b). At $96 \mathrm{hpf}$, the body length was also comparable among all groups (Figure 8c).

(a)

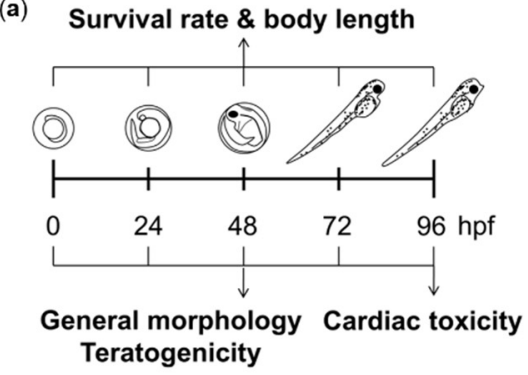

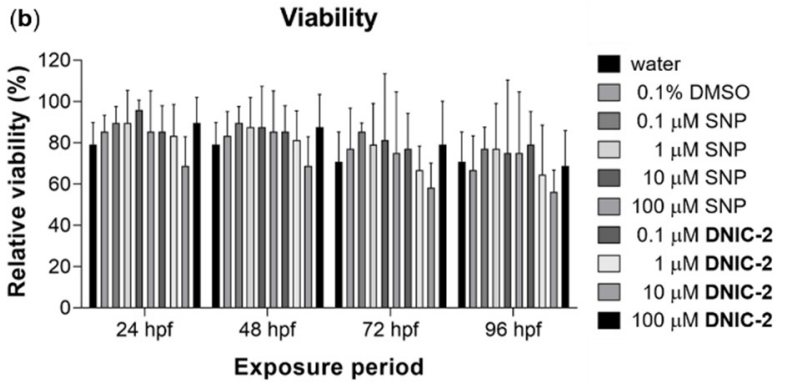

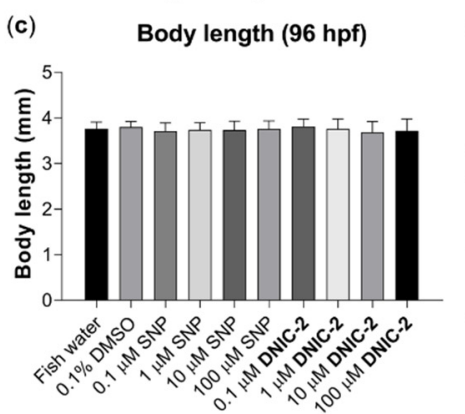

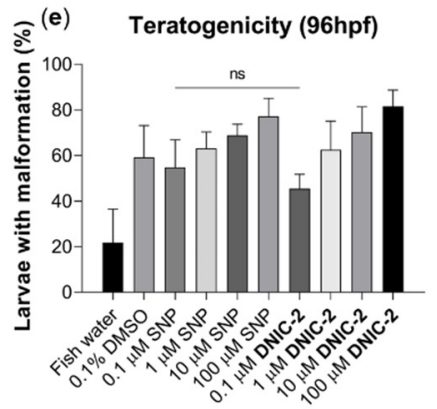

Figure 8. Comparison of developmental toxicity of DNIC-2 and SNP in embryonic zebrafish. (a) Experimental design for ZET assay. (b) Viability of zebrafish embryos upon exposure to different concentrations of DNIC-2 (or SNP) for alternative durations. (c) Body length for DNIC-2- or SNP-treated zebrafish larvae at 96 hpf. (d) General morphology score for DNIC-2or SNP-treated zebrafish larvae at 96 hpf. (e) Fraction of larvae with at least one teratogenic effect at 96 hpf. One-way ANOVA with Holm-Šidák test; ns, no significance. Data are expressed as mean + SD ( $=4, n=7-12)$.

To further investigate the toxicity of DNIC-2 on embryonic development, a general morphology scoring system was adopted to evaluate developmental timing and the occurrence of teratogenicity [61]. As shown in Figure 8d, no delay or hastening of embryonic development was observed in DNIC-2-treated and SNP-treated groups in comparison with the control group at $96 \mathrm{hpf}$. For teratogenic assessment, the number of larvae with one or more abnormal anatomical phenotypes at $96 \mathrm{hpf}$ was recorded, and the fraction of larvae with malformation was calculated to infer teratogenicity. The analysis revealed teratogenic tendency seemed to increase in a dose-dependent manner in both DNIC-2-treated and SNP-treated groups (Figure 8e). Collectively, these data suggested that the effects of DNIC-2 on zebrafish developmental toxicity were equivalent to that of SNP.

Upon treatment of zebrafish embryos with different concentrations of DNIC-2 (or $\mathrm{SNP}$ ), the heart rate, the distance between sinus venosus (SV) and bulbus arteriosus (BA), the incidence of pericardial edema, and the edema index were further investigated in order to assess the potential cardiac toxicity of DNIC-2 and SNP. At $96 \mathrm{hpf}$, no significant difference in heart rate and SV-BA distance was observed among all groups (Figure 9a-c), which suggests the absent toxicity of DNIC-2 and SNP on embryonic heart development. Based on the value of SV-BA distance, the severity of pericardial edema is classified into three categories: normal, mild, and severe groups as shown in Figure $9 \mathrm{~d}-\mathrm{f}$. As shown in Figure $9 \mathrm{~g}$, a treatment of $0.1 \mu \mathrm{M}$ of DNIC-2 to zebrafish embryos induced significantly less incidence of pericardial edema than $0.1 \mu \mathrm{M}$ of SNP treatment. Of interest, DNIC-2 features a linear trend of dose-dependent induction of cardiac edema, while an exponential trend of dose-dependent induction of cardiac edema was observed when the zebrafish embryo was 
treated with SNP (Figure 9h). On the other hand, the pericardial edema index indicates similar dose-dependent toxicity of both DNIC-2 and SNP (Figure 9i). Accordingly, DNIC-2 demonstrates better biocompatibility than SNP regarding the potential zebrafish embryo cardiac toxicity.

(a)

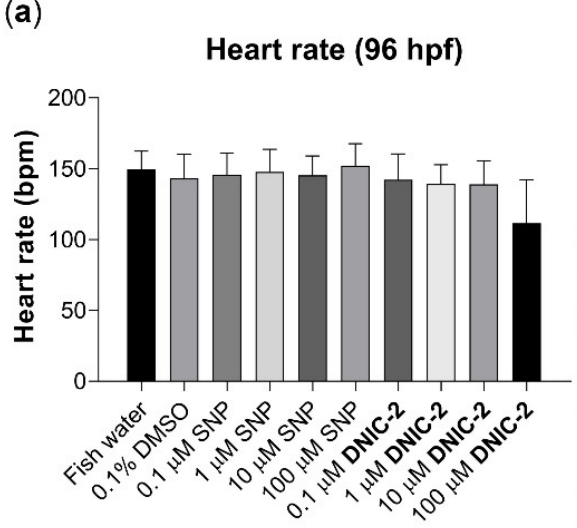

(d)
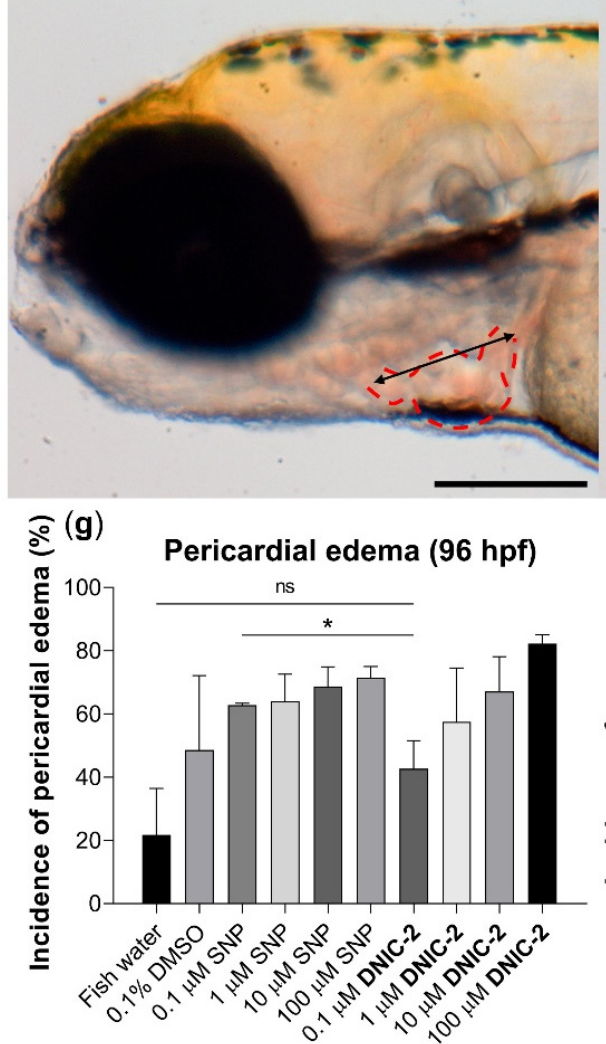

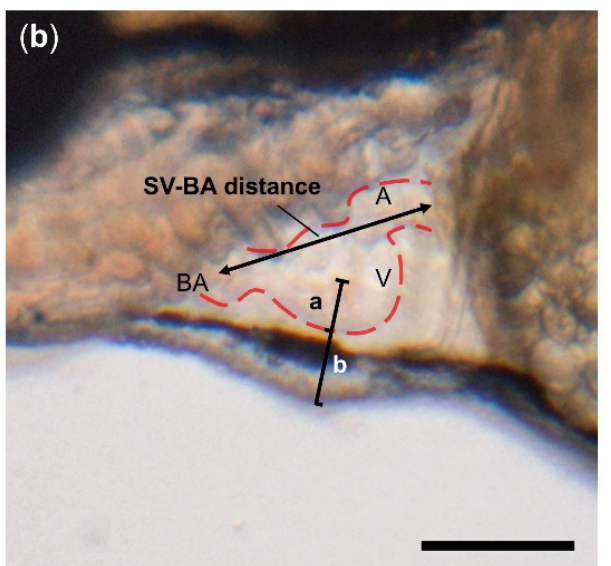

(e)

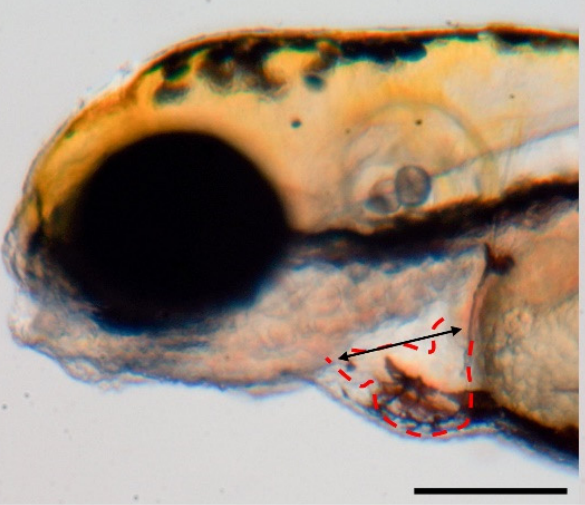

(h)

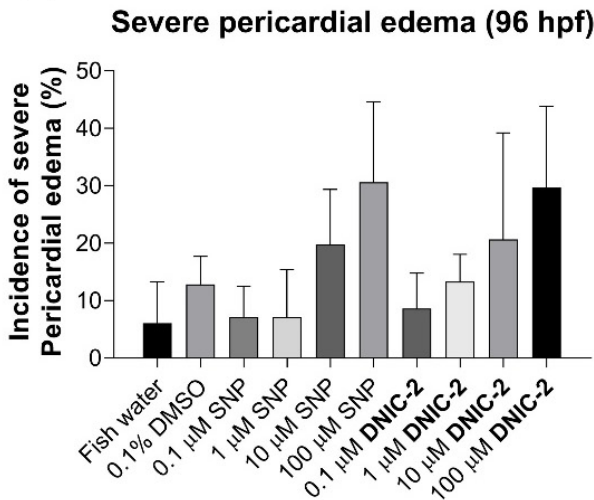

(c)

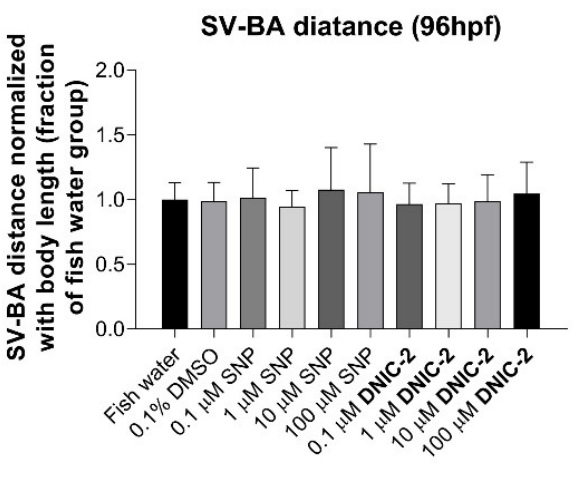

(f)

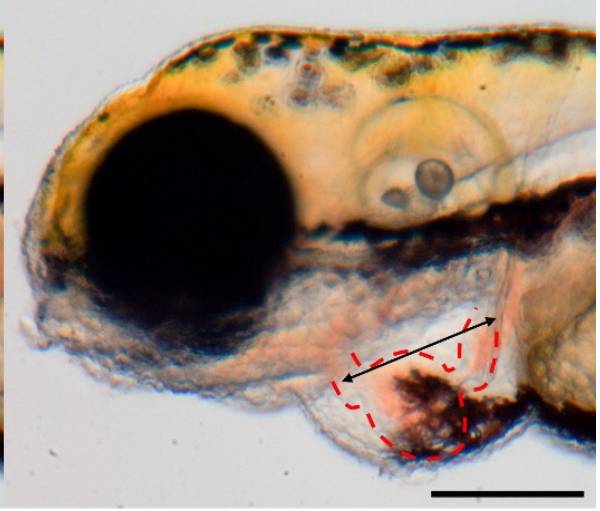

(i)

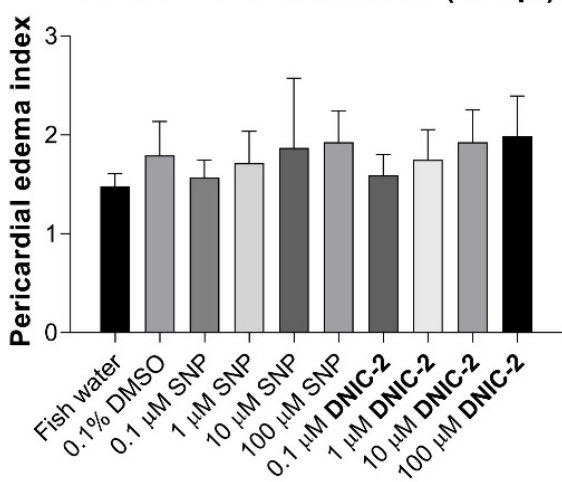

Figure 9. Treatment of DNIC-2 induced less severe pericardial edema than SNP in zebrafish embryos. (a) Heart rate for zebrafish embryos at $96 \mathrm{hpf}$ in the control, DNIC-2-treated, and SNP-treated groups. (b) Graphical illustration of SV-BA distance and edema index. The measurement of SV-BA distance was indicated with a black arrow, whereas edema index was defined as the ratio of the semi-diameter of the pericardial cavity to that of the ventricle (b/a). Scale bar $=100 \mu \mathrm{m}$. (c) SV-BA distance normalized with body length. (d-f) Representative images of cardiac edema in different categories based on SV-BA measurement; the measurement points were indicated by arrows. The hearts were indicated by red dotted lines. Scale bar $=200 \mu \mathrm{m}$. (g) Fraction of larvae with cardiac edema at 96 hpf. (h) Incidence of severe cardiac edema at 96 hpf. (i) Pericardial edema index at 96 hpf. One-way ANOVA with Holm-Šidák test; ${ }^{*} p<0.05$; ns, no significance. Data are expressed as mean $+\mathrm{SD}(\mathrm{N}=4, n=7-12)$. 
According to the zebrafish embryotoxicity test (ZET) results described above, pericardial edema induced by NO-delivery DNIC-2 and SNP, presumably, can be ascribed to the excessive nitrite derived from the oxidation of released nitric oxide [62]. Excessive nitrite was reported to trigger abnormal heart development of zebrafish embryos and to affect the development of the nervous system or muscles [62]. Another potential mechanism for dose-dependent pericardial edema induced by DNIC-2 (or SNP) in zebrafish embryos is excessive NO-sGC-cGMP signaling, which awaits further verification by exploring the histological and molecular changes of DNIC-2-treated embryos with cGMP signaling antagonist [62].

\section{Materials and Methods}

Complex $\left[\mathrm{Fe}_{2}\left(\mu-\mathrm{SCH}_{2} \mathrm{CH}_{2} \mathrm{COOH}\right)_{2}(\mathrm{NO})_{4}\right]$ (DNIC-2) was synthesized based on published procedures [36]. UV-vis spectra were recorded on a Perkin-Elmer Lambda 365 spectrometer. EPR measurements were performed at X-band using a Bruker EMXmicro-6/1/S/L spectrometer equipped with a Bruker E4119001 super high sensitivity cavity. X-band EPR spectra were obtained with a microwave power of $20.27-20.54 \mathrm{~mW}$, the frequency at $9.41 \mathrm{GHz}$, conversion time of $66.68 \mathrm{~ms}$, receiver gain of 30, and modulation amplitude of $10.0 \mathrm{G}$ at $100 \mathrm{KHz}$. Fluorescence intensity was recorded using a microplate reader (SpectraMax iD3, Molecular Devices, San Jose, CA, USA). Fluorescence images were taken using a fluorescence microscope (Olympus, CKX53, Tokyo, Japan).

Degradation and NO-release Reactivity of DNIC-2 in MEM. The aqueous solution for $50 \mu \mathrm{M}$ of DNIC-2 was prepared via the addition of $15 \mu \mathrm{L}$ of a $50-\mathrm{mM}$ stock solution of DNIC-2 in DMSO to $14.85 \mathrm{~mL}$ of MEM. After this solution was incubated at $37^{\circ} \mathrm{C}$ under aerobic conditions for $0,1,2,3,4,5,6,7,8,10,12,16$, and $24 \mathrm{~h}$, UV-vis spectra were measured in order to evaluate the degradation of DNIC-2 based on the absorbance at $362 \mathrm{~nm}$. Assuming that the degradation of DNIC-2 follows pseudo-first-order kinetics, the rate for the decrease of $\mathrm{A}_{362}$ was calculated to determine the half-life of DNIC-2 in MEM at $37^{\circ} \mathrm{C}$. Three independent experiments were executed to measure the average half-life for DNIC-2. The average half-life for DNIC-2 in MEM with the presence of $10 \% \mathrm{FBS}$ at $37^{\circ} \mathrm{C}$ was determined in a similar manner.

After the incubation of $25 \mu \mathrm{M}$ of DNIC-2 in MEM with or without the presence of $10 \%$ FBS under aerobic condition for two days, the equivalent of nitric oxide released from degradation of DNIC-2 was evaluated using Nitrate/Nitrite Colorimetric Assay Kit (Item No. 780001, Cayman Chemical, Ann Arbor, MI, USA). A general procedure is described below. After $10 \mu \mathrm{L}$ of the aqueous solution derived from degradation of DNIC-2 was diluted with $70 \mu \mathrm{L}$ of kit assay buffer, $10 \mu \mathrm{L}$ of Nitrate Reductase Cofactors (Item No. 780012) and $10 \mu \mathrm{L}$ of Nitrate Reductase Enzyme (Item No. 780010) were added before this mixture solution was covered and incubated at room temperature for $2 \mathrm{~h}$. The subsequent addition of $50 \mu \mathrm{L}$ of Griess Reagent R1 (Item No. 780018) and $50 \mu \mathrm{L}$ of Griess Reagent R2 (Item No. 780020) followed by incubation at room temperature for $15 \mathrm{~min}$ results in the formation of a UV-vis absorption band at $540 \mathrm{~nm}$. The absorbance at $540 \mathrm{~nm}$ was then recorded using a microplate reader (SpectraMax iD3, Molecular Devices, San Jose, CA, USA) with a reference wavelength of $800 \mathrm{~nm}$. According to a calibration curve made with $0,5,10,15,20,25,30$, and $35 \mu \mathrm{M}$ of nitrite standard (Item No. 780016)/nitrate standard (Item No. 780014), the equivalent of nitric oxide released from the degradation of DNIC-2 was further estimated.

The NO-release reactivity of DNIC-2 was also validated using the fluorescence probe 4-amino-5-methylamino-2', $7^{\prime}$-difluorofluorescein diacetate (DAF-FM, ThermoFisher Scientific, Waltham, MA, USA). In a 96-well black plate, $50 \mu \mathrm{M}$ of DNIC-2 and $10 \mu \mathrm{M}$ of DAF-FM in MEM with the presence of $10 \%$ FBS was incubated under aerobic conditions at $37^{\circ} \mathrm{C}$ for $0,0.5,1,2,4,6$, and $8 \mathrm{~h}$. With an excitation wavelength at $495 \mathrm{~nm}$ and an emission wavelength at $535 \mathrm{~nm}$, fluorescence intensity was then recorded using a microplate reader (SpectraMax iD3, Molecular Devices, San Jose, CA, USA). Three independent experiments were executed to measure the average fluorescence intensity. The time-dependent change of 
average fluorescence intensity for $10 \mu \mathrm{M}$ DAF-FM with or without the treatment of $133 \mu \mathrm{M}$ of diethylamine NONOate sodium salt hydrate (DEANO, Sigma-Aldrich, St. Louis, MO, USA) in MEM with the presence of $10 \%$ FBS at $37^{\circ} \mathrm{C}$ was determined in a similar manner.

Formation of Protein-bound DNIC upon Incubation of DNIC-2 in MEM. After the addition of $50 \mu \mathrm{M}$ of DNIC-2 into $1 \mathrm{~mL}$ of MEM with or without the presence of $10 \%$ FBS, the formation of protein-bound DNIC derived from the reaction of DNIC-2 with serum albumin $(2.1 \mathrm{mg} / \mathrm{mL})$ was characterized by EPR spectroscopy. Using DNIC $[\mathrm{PPN}]\left[(\mathrm{NO})_{2} \mathrm{Fe}\left(\mathrm{S}_{5}\right)\right]$ as a standard, the formation of protein-bound DNIC was quantified based on the calibration curve derived from the EPR spectra of 1, 5, 10, 20, 30, 40, and $50 \mu \mathrm{M}$ of DNIC [PPN][(NO) $\left.{ }_{2} \mathrm{Fe}\left(\mathrm{S}_{5}\right)\right]$ in THF.

Cell culture. CCD-966Sk human skin fibroblasts and B16-F10 mouse skin melanoma cells were purchased from Bioresource Collection and Research Center, Food Industry Research and Development Institute (Hsinchu, Taiwan), whereas human skin keratinocyte cell line, HaCaT, was purchased from Elabscience Biotechnology Inc. (Elabscience ${ }^{\circledR}$ EPCL-0090, Houston, TX, USA). CCD-966Sk cells were cultured in MEM supplemented with 10\% FBS, $0.1 \mathrm{mM}$ non-essential amino acids, $1 \mathrm{mM}$ sodium pyruvate, and 1\% antibioticantimycotic mixture (all from ThermoFisher Scientific, Waltham, MA, USA). B16-F10 cells were cultivated in Dulbecco's modified Eagle's medium (phenol red-free; ThermoFisher Scientific, Waltham, MA, USA) supplemented with 10\% FBS, $4 \mathrm{mM}$ L-glutamine, and 1\% antibiotic-antimycotic mixture. HaCaT cells were cultured in Dulbecco's modified Eagle's medium (DMEM; \#12100-046, ThermoFisher Scientific, Waltham, MA, USA) containing 5\% fetal bovine serum (\#10082-147, ThermoFisher Scientific, Waltham, MA, USA) and 1\% PSG (Penicillin-Streptomycin-Glutamine (100X) containing 10,000 units of penicillin, 10,000 $\mu \mathrm{g}$ of streptomycin, and $29.2 \mathrm{mg} / \mathrm{mL}$ of L-glutamine in a $10 \mathrm{mM}$ citrate buffer (\#10378016, ThermoFisher Scientific, Waltham, MA, USA). All cells were grown in a T75 flask at $37{ }^{\circ} \mathrm{C}$ with $5 \% \mathrm{CO}_{2}$ in a humidified incubator. The culture medium was refreshed every other day.

Cellular uptake of DNIC-2 by CCD-966Sk human fibroblast cells. CCD-966Sk human fibroblast cells were seeded into a $100-\mathrm{mm}$ dish at a density of $1 \times 10^{6}$ cells and incubated at $37^{\circ} \mathrm{C}$ overnight. The next day, CCD-966Sk human fibroblast cells were treated with $50 \mu \mathrm{M}$ of DNIC-2 and incubated for $0,0.5,1,4$, and $8 \mathrm{~h}$, respectively. After removal of the supernatant solution, CCD-966Sk human fibroblast cells were further washed with DPBS before the addition of $1 \mathrm{~mL}$ of trypsin/EDTA $(0.05 \% / 0.53 \mathrm{mM})$ and incubation for $5 \mathrm{~min}$ at $37^{\circ} \mathrm{C}$. After the obtained cell suspension solution was further centrifuged at $1000 \times g$ for $5 \mathrm{~min}$, the supernatant was removed before the addition of $100 \mu \mathrm{L}$ of MEM. This solution was then transferred into the EPR quartz tube and frozen in $\mathrm{N}_{2(1)}$ before the EPR measurements.

Intracellular release of nitric oxide from DNIC-2 in CCD-966Sk human fibroblast cells. Intracellular delivery of nitric oxide by DNIC-2 was validated using the fluorescence probe 4-amino-5-methylamino-2', $7^{\prime}$-difluorofluorescein diacetate (DAF-FM). CCD-966Sk human fibroblast cells were seeded into a 96-well black plate at a density of $2.5 \times 10^{3}$ cells and incubated at $37^{\circ} \mathrm{C}$ overnight. The next day, CCD-966Sk human fibroblast cells were first treated with $10 \mu \mathrm{M}$ of DAF-FM and incubated at $37^{\circ} \mathrm{C}$ for $1 \mathrm{~h}$. After removal of the supernatant solution, CCD-966Sk human fibroblast cells were further washed with DPBS. Then, $50 \mu \mathrm{M}$ of DNIC-2 was added and incubated for 0, 0.5, 1, 2, 4, and $8 \mathrm{~h}$, respectively, in the dark. The fluorescence intensity of the cells was then recorded using a microplate reader (SpectraMax iD3, Molecular Devices, San Jose, CA, USA) with an excitation wavelength at $495 \mathrm{~nm}$ and an emission wavelength at $535 \mathrm{~nm}$. Three independent experiments were executed to measure the time-dependent change of average fluorescence intensity. The timedependent change of average fluorescence intensity for the CCD-966Sk human fibroblast cells with the treatment of $10 \mu \mathrm{M}$ of DAF-FM or with the sequential treatment of $10 \mu \mathrm{M}$ of DAF-FM and $133 \mu \mathrm{M}$ of DEANO was determined in a similar manner. On the other hand, fluorescence images of the CCD-966Sk human fibroblast cells with the treatment of $10 \mu \mathrm{M}$ of DAF-FM, with the sequential treatment of $10 \mu \mathrm{M}$ of DAF-FM and $50 \mu \mathrm{M}$ of DNIC-2, and 
with the sequential treatment of $10 \mu \mathrm{M}$ of DAF-FM and $133 \mu \mathrm{M}$ of DEANO, respectively, were also taken using a fluorescence microscope (Olympus, CKX53, Tokyo, Japan).

Biological activities of DNIC-2 toward skin fibroblasts. To evaluate the effects of DNIC-2 on fibroblast viability, CCD-966SK cells grown in a 96-well plate (2500 cells/well) were treated with various dosages of DNIC-2. After incubation for $24 \mathrm{~h}$, cell viability was determined using a CCK-8 assay (IMT Formosa New Materials, Kaohsiung, Taiwan). Alternatively, the grown cells were stained with $0.5 \mu \mathrm{g} / \mathrm{mL}$ DAPI (ThermoFisher Scientific, Waltham, MA, USA) for $20 \mathrm{~min}$, their nuclei were visualized and counted under a fluorescence microscope (Axio Observer 7; Carl Zeiss, Oberkochen, Germany). For each well, six visual fields were selected randomly for nuclei counting. Moreover, live/dead staining was performed using a ViaQuant Viability/Cytotoxicity Kit (GeneCopoeia, Rockville, MD, USA) according to the manufacturer's instruction.

For the scratch wound healing assay, CCD-966SK cells were seeded into a 24-well plate $\left(4 \times 10^{4}\right.$ cells/well). After a 24 -h culture, a P200 tip was utilized to scratch the cellular monolayer to create a cell-free wound in each well. The culture medium was then substituted with a fresh medium with or without DNIC-2. The migration of cells into the gap region was photographed under a microscope, and the remaining wound area was determined using ImageJ software [63,64].

To assess the effects of DNIC-2 on the collagen deposition behavior of skin fibroblasts, CCD-966SK cells were cultured in a 48-well plate (7500 cells/well) for 7 days. The culture medium was replaced with fresh medium with DNIC-2 every day. To evaluate the collagen content, cells were fixed with $4 \%$ paraformaldehyde (Sigma-Aldrich, St. Louis, MO, USA) for 15 min and stained with a Sirius Red/Fast Green Collagen Staining Kit (Chondrex, Woodinville, WA, USA) according to the manufacturer's protocol [65]. The stained cells were photographed under a microscope before subjecting to dye extraction. The optical density of the extracted dye at $540 \mathrm{~nm}$ was determined using a microplate reader to quantify the collagen content of test samples.

Biological activities of DNIC-2 toward skin melanocytes. The B16-F10 cells were inoculated into a 12-well plate at a density of $4 \times 10^{4}$ cells per well and incubated for $24 \mathrm{~h}$. Subsequently, under the stimulation of $\alpha-\mathrm{MSH}$ (200 nM; Sigma-Aldrich, St. Louis, MO, USA), cells were treated with different concentrations of DNIC-2 or $2 \mathrm{mM}$ of arbutin (Sigma-Aldrich, St. Louis, MO, USA) for $48 \mathrm{~h}$ [66-68]. To determine the amount of the melanin secreted by the grown cells, the absorbance of the culture medium at $405 \mathrm{~nm}$ was measured using a microplate reader. To quantify the intracellular melanin content, the cells were washed with PBS, trypsinized, pelleted by centrifugation, lysed using $1 \mathrm{~N} \mathrm{NaOH}$ at $70{ }^{\circ} \mathrm{C}$ for $1 \mathrm{~h}$, and analyzed using a microplate reader to measure the optical density at $405 \mathrm{~nm}$ [66-68].

To determine the activity of tyrosinase, the cells prepared according to the aforementioned methods were lysed with RIPA buffer $(20 \mathrm{mM}$ Tris-HCl, $1 \mathrm{mM}$ EGTA, $150 \mathrm{mM} \mathrm{NaCl}$, and $1 \%$ Triton $\mathrm{X}-100$ ) [69] at $4{ }^{\circ} \mathrm{C}$ for $20 \mathrm{~min}$ followed by centrifugation at $14,000 \mathrm{rpm}$ for $15 \mathrm{~min}$. A bicinchoninic acid assay (G-Biosciences, St. Louis, MO, USA) was used to quantify the total protein of the supernatant. The supernatant that contained $40 \mu \mathrm{g}$ protein (adjusted to $100 \mu \mathrm{L}$ with $0.1 \mathrm{mM}$ sodium phosphate buffer; $\mathrm{pH}$ 6.8) was mixed with $100 \mu \mathrm{L}$ of freshly prepared L-DOPA ( $5 \mathrm{mM}$; Sigma-Aldrich, St. Louis, MO, USA) and incubated at $37^{\circ} \mathrm{C}$ for $1 \mathrm{~h}[66,70]$. Finally, the relative tyrosinase activity of samples was determined by measuring the optical density of the reaction mixture at $475 \mathrm{~nm}$ using a microplate reader and normalized to that of the untreated control group.

Cell viability assay of DNIC-2 toward keratinocyte. To evaluate the effects of DNIC-2 on keratinocyte viability, HaCaT cells grown in a 96-well plate $\left(2 \times 10^{5}\right.$ cells /well $)$ were treated with various dosages of DNIC-2. After incubation for $24 \mathrm{~h}$, cell viability was determined using an MTT assay (Sigma Aldrich, St. Louis, MO, USA).

In Vitro Skin Irritation Test by Reconstructed human Epidermis Model. The validated EPI-200-SIT protocol and the Reconstructed human Epidermis (RhE) model EpiDerm ${ }^{\mathrm{TM}}$ provided by MatTek Life Sciences (Ashland, MA, USA) were used for the in vitro skin 
irritation test (SIT). EpiDerm ${ }^{\mathrm{TM}}$ SIT was performed to fulfill the criteria set forth in OECD TG 439 [71]. The EpiDerm ${ }^{\mathrm{TM}}$ skin inserts were transferred to 6-well plates containing $0.9 \mathrm{~mL}$ EPI-100-NMM-SIT / Assay Medium (MatTek Life Sciences) per well and pre-incubated in the humidified incubator with $5 \% \mathrm{CO}_{2}$ at $37{ }^{\circ} \mathrm{C}$ overnight. Before conducting the SIT test, the assay medium was replaced by the fresh medium and $35 \mu \mathrm{L}$ of DNIC-2 (50 $\mu \mathrm{M})$ was applied topically on top of the EpiDerm ${ }^{\mathrm{TM}}$ skin surface for $60 \mathrm{~min}$. Then, DPBS was used to rinse the EpiDerm ${ }^{\mathrm{TM}}$ skin surface gently several times, and finally, a sterile cotton swab was gently used to remove excess water and avoid touching the tissue. After that, the EpiDerm ${ }^{\mathrm{TM}}$ skin insert was placed in an incubator with $5 \% \mathrm{CO}_{2}$ at $37{ }^{\circ} \mathrm{C}$ for $24 \mathrm{~h}$. Then, the tissue was transferred to a 6-well plate that had been added with a new proprietary medium and incubated again for $18 \pm 2 \mathrm{~h}$. After the EpiDerm ${ }^{\mathrm{TM}}$ skin inserts were rinsed with PBS twice, $2 \mathrm{~mL}$ of MTT reagent (MatTek Life Sciences) was added to the EpiDerm ${ }^{\mathrm{TM}}$ skin inserts, which were further incubated in a $5 \% \mathrm{CO}_{2}$ environment for $3 \mathrm{~h}$ before the MTT assay. $2 \mathrm{~mL}$ of isopropanol was used to extract formazan. The optical density (OD) of $200 \mu \mathrm{L}$ of the isopropanol extract was measured at $570 \mathrm{~nm}$ using a UV-Vis Spectrophotometer (BioTeK, Winooski, VT, USA). $50 \mu \mathrm{M}$ of DNIC-2 was considered to be an irritant to the skin if the tissue viability after exposure was $\leq 50 \%$. In addition, $5 \%$ SDS (Sodium dodecyl sulfate, MatTek Life Sciences, Ashland, MA, USA) was used as a positive control, while DPBS (MatTek Life Sciences, Ashland, MA, USA) was used as a negative control. Three replicates of EpiDerm ${ }^{\mathrm{TM}}$ skin inserts were used for each experiment.

In Vitro Eye Irritation Test by Reconstructed human Cornea-like Epithelium Model. The validated EPI-200-EIT protocol and the Reconstructed human Cornea-like Epithelium (RhCE) model EpiOcular ${ }^{\mathrm{TM}}$ provided by MatTek Life Sciences (Ashland, MA, USA) were used for the in vitro eye irritation test (EIT). EpiOcular ${ }^{\text {TM }}$ EIT was performed to fulfill the criteria set forth in OECD TG 492 [72]. The EpiOcular ${ }^{\mathrm{TM}}$ cornea inserts were transferred to 6-well plates containing 0.9 mL OCL-200-ASY-Assay Medium (MatTek Life Sciences, Ashland, MA, USA) per well and pre-incubated in the humidified incubator with $5 \%$ $\mathrm{CO}_{2}$ at $37^{\circ} \mathrm{C}$ overnight. Before conducting the SIT test, the assay medium was replaced by the fresh medium and $50 \mu \mathrm{L}$ of DNIC-2 $(50 \mu \mathrm{M})$ was applied topically on top of the EpiOcular ${ }^{\mathrm{TM}}$ cornea surface for $30 \mathrm{~min}$. Then, DPBS was used to rinse the EpiOcular ${ }^{\mathrm{TM}}$ cornea surface gently several times, and finally, a sterile cotton swab was used to remove excess water and avoid touching the tissue. After that, the EpiOcular ${ }^{\mathrm{TM}}$ cornea tissue was soaked in a $5 \mathrm{~mL}$ culture medium for $12 \mathrm{~min}$, then transferred to a 12-well plate that had been added with a new proprietary medium, and incubated again for $2 \mathrm{~h}$. Afterward, $2 \mathrm{~mL}$ of MTT reagent (MatTek Life Sciences, Ashland, MA 01721) and $2 \mathrm{~mL}$ of the medium were added to the EpiDerm ${ }^{\mathrm{TM}}$ skin inserts, which were further incubated in a $5 \% \mathrm{CO}_{2}$ environment for $3 \mathrm{~h}$ before the MTT assay. Furthermore, $2 \mathrm{~mL}$ of isopropanol was added to the EpiOcular ${ }^{\mathrm{TM}}$ cornea inserts and incubated overnight to extract formazan. The optical density (OD) of $200 \mu \mathrm{L}$ of the isopropanol extract was measured at $570 \mathrm{~nm}$ using a UV-Vis Spectrophotometer (BioTeK, Winooski, VT, USA). $50 \mu \mathrm{M}$ of DNIC-2 was considered to be an irritant to the eyes if the tissue viability after exposure was $\leq 60 \%$. In this study, $100 \%$ Methyl Acetate (MatTek Life Sciences, Ashland, MA, USA) was used as a positive control, while DPBS (MatTek Life Sciences, Ashland, MA, USA) was used as a negative control. Three replicates of EpiOcular ${ }^{\mathrm{TM}}$ cornea inserts were used for each experiment.

Zebrafish embryotoxicity test (ZET). All procedures involving animals were approved by the institutional animal experiments committees and performed in compliance with animal welfare laws, guidelines, and policies. (IACUC No. 109022). ZET was carried out following the reported protocol with modifications [61]. Zebrafish embryos were prepared by natural spawning from adult zebrafish and were exposed to DNIC-2 (or SNP) at different concentrations (between 0.1 and $100 \mu \mathrm{M}$ ) in $2 \mathrm{~mL}$ of fresh water from $4 \mathrm{hpf}$ to $96 \mathrm{hpf}$ using 24-well culture plates (4 embryos in $2 \mathrm{~mL}$ solution/well). The aqueous solution of DNIC-2 (or SNP) was renewed every $24 \mathrm{~h}$ and the viability of embryos was recorded at the same time. At $48 \mathrm{hpf}$, the chorion membrane of zebrafish embryos was removed carefully to ensure same exposure condition among all embryos. 
To explore the effect of DNIC-2 (or SNP) on zebrafish embryo development, zebrafish embryos were anesthetized with a drop of 2000-ppm tricaine (Sigma-Aldrich, St. Louis, MO, USA), and then mounted with $2 \%$ agarose (Lonza, Basel, Switzerland). Morphological evaluation of zebrafish embryos was performed at $96 \mathrm{hpf}$ using a general morphology scoring system, [61] which comprises the developmental phase up to $96 \mathrm{hpf}$.

After treatment of different concentrations of DNIC-2 (or SNP), the heart rate, presence of pericardial edema, and the SV-BA distance in zebrafish embryos were examined to assess drug-induced cardiotoxicity. The evaluation protocol of pericardial edema was modified from previous studies [62,73]. The SV-BA distance normalized to the body length was used to monitor the formation of embryonic heart tubes [74]. The pericardial edema index was defined as the ratio of the semi-diameter of the pericardial cavity to that of the ventricle, which reflects the severity of pericardial edema [62]. Body length, SV-BA distance, and pericardial edema index were measured from a lateral view and processed with Image J software after capturing images using a stereoscopic zoom microscope (SMZ1500; Nikon, Tokyo, Japan) with a microscope camera (DS-Ri2; Nikon, Tokyo, Japan).

\section{Conclusions}

A mechanistic and efficacy study of the cell-penetrating delivery of NO by DNIC-2 and its regulatory effect on dermato-physiology has led to the following results. DNIC-2 displays a release of $\sim 4$ equiv. of $\mathrm{NO}$ with a comparable half-life of $4.2 \pm 0.6 / 3.5 \pm 0.3 \mathrm{~h}$ in MEM with and without the presence of $10 \%$ FBS, respectively. Upon treatment of DNIC-2 to CCD-966SK human skin fibroblast cells, cellular uptake of DNIC-2 followed by its intracellular transformation into protein-bound DNICs rationalizes the steady and effective release of $\mathrm{NO}$ with an intracellular half-life of $1.8 \pm 0.2 \mathrm{~h}$, which overwhelms the NO donor diethylamine NONOate (DEANO). The treatment of skin fibroblasts with low-dose DNIC-2 resulted in enhanced cell proliferation, migration, and collagen deposition, thus holding substantial potential for dermatological applications. On the other hand, the application of DNIC-2 to melanoma cells did not lead to significant alternation in melanogenesis. Based on the biocompatibility evaluation using a 2-D culture of fibroblast/melanocyte/keratinocyte cells, the 3-D culture of reconstructed human epidermis and human cornea-like epithelium models, and zebrafish embryo toxicity assay, DNIC-2 holds the potential for further development as a novel active ingredient for skincare products.

Supplementary Materials: The following are available online at https:/ / www.mdpi.com/article/10 $.3390 /$ ijms221810101/s1.

Author Contributions: H.C. performed experiments and prepared Figures 3-7; Y.-C.C. and Y.-H.K. performed experiments and prepared Figures 8 and 9; Y.-H.C. performed experiments and prepared Figures 1 and 2; R.-T.W. and W.-P.W. edited the manuscript text. Y.-J.C., C.-C.H. and T.-T.L. supervised the study and wrote the manuscript text. All authors have read and agreed to the published version of the manuscript.

Funding: This research was funded by the Ministry of Science and Technology, Taiwan, grant number MOST 109-2628-M-007-003-MY3, MOST 109-2622-M-007-003-CC2, and MOST 110-2622-M-007-002; National Tsing Hua University, grant number 109Q2711E1 and 110Q2711E1.

Institutional Review Board Statement: The study was conducted according to the guidelines of the animal protection standards, and the animal use and experimental protocols had been approved by the Experimental Animal Care and Use Committee of National Tsing Hua University, Hsinchu, Taiwan.

Acknowledgments: We thank ImDerma Laboratories Co., Ltd. for the support on OECD TG 439 Skin Irritation Test and OECD TG 492 Eye Irritation Test.

Conflicts of Interest: The authors declare no conflict of interest. 


\section{References}

1. Nalbandyan, R.M.; Vanin, A.F.; Blumenfeld, L.A. Free radicals in yeast cells. In Proceedings of the Meeting “Free Radicals Processes in Biological Systems", Moscow, Russia; 1964; p. 18.

2. Vanin, A.F.; Nalbandian, R.M. Free Radicals of a New Type in Yeast Cells. Biofizika 1965, 10, 167-168.

3. Vanin, A.F.; Nalbandyan, R.M. Free radical species with unpaired electron localization on sulfur atom in yeast cells. Biofizika 1966, 11, 178-179. [PubMed]

4. Vithayathil, A.J.; Ternberg, J.L.; Commoner, B. Changes in electron spin resonance signals of rat liver during chemical carcinogenesis. Nature 1965, 207, 1246-1249. [CrossRef] [PubMed]

5. Vanin, A.F.; Kubrina, L.N.; Kiladze, S.V.; Burbaev, D. Factors influencing formation of dinitrosyl complexes of non-heme iron in vitro preparations of mouse liver and yeasts. Biofizika 1977, 22, 646-650. [PubMed]

6. Vanin, A.F.; Kiladze, S.V.; Kubrina, L.N. Factors influencing formation of dinitrosyl complexes of non-heme iron in the organs of animals in vivo. Biofizika 1977, 22, 850-855. [PubMed]

7. Rogers, P.A.; Ding, H. L-cysteine-mediated destabilization of dinitrosyl iron complexes in proteins. J. Biol. Chem. 2001, 276, 30980-30986. [CrossRef]

8. Yang, W.; Rogers, P.A.; Ding, H. Repair of nitric oxide-modified ferredoxin [2Fe-2S] cluster by cysteine desulfurase (IscS). J. Biol. Chem. 2002, 277, 12868-12873. [CrossRef]

9. Tinberg, C.E.; Tonzetich, Z.J.; Wang, H.; Do, L.H.; Yoda, Y.; Cramer, S.P.; Lippard, S.J. Characterization of iron dinitrosyl species formed in the reaction of nitric oxide with a biological Rieske center. J. Am. Chem. Soc. 2010, 132, 18168-18176. [CrossRef] [PubMed]

10. Ekanger, L.A.; Oyala, P.H.; Moradian, A.; Sweredoski, M.J.; Barton, J.K. Nitric Oxide Modulates Endonuclease III Redox Activity by a $800 \mathrm{mV}$ Negative Shift upon $\left[\mathrm{Fe}_{4} \mathrm{~S}_{4}\right]$ Cluster Nitrosylation. J. Am. Chem. Soc. 2018, 140, 11800-11810. [CrossRef]

11. Bosworth, C.A.; Toledo, J.C., Jr.; Zmijewski, J.W.; Li, Q.; Lancaster, J.R., Jr. Dinitrosyliron complexes and the mechanism(s) of cellular protein nitrosothiol formation from nitric oxide. Proc. Natl. Acad. Sci. USA 2009, 106, 4671-4676. [CrossRef]

12. Tsai, M.-L.; Chen, C.-C.; Hsu, I.-J.; Ke, S.-C.; Hsieh, C.-H.; Chiang, K.-A.; Lee, G.-H.; Wang, Y.; Chen, J.-M.; Lee, J.-F.; et al. Photochemistry of the dinitrosyl iron complex $\left[\mathrm{S}_{5} \mathrm{Fe}(\mathrm{NO})_{2}\right]^{-}$leading to reversible formation of $\left[\mathrm{S}_{5} \mathrm{Fe}(\mu-\mathrm{S})_{2} \mathrm{FeS}\right]_{5}^{2-}: \mathrm{Spectroscopic}$ characterization of species relevant to the nitric oxide modification and repair of [2Fe-2S] ferredoxins. Inorg. Chem. 2004, 43, 5159-5167. [CrossRef]

13. Harrop, T.C.; Song, D.; Lippard, S.J. Interaction of nitric oxide with tetrathiolato iron(II) complexes: Relevance to the reaction pathways of iron nitrosyls in sulfur-rich biological coordination environments. J. Am. Chem. Soc. 2006, 128, 3528-3529. [CrossRef]

14. Tsai, M.-L.; Tsou, C.-C.; Liaw, W.-F. Dinitrosyl iron complexes (DNICs): From biomimetic synthesis and spectroscopic characterization toward unveiling the biological and catalytic roles of DNICs. Acc. Chem. Res. 2015, 48, 1184-1193. [CrossRef]

15. Fitzpatrick, J.; Kim, E. Synthetic modeling chemistry of iron-sulfur clusters in nitric oxide signaling. Acc. Chem. Res. 2015, 48, 2453-2461. [CrossRef]

16. Pereira, J.C.; Iretskii, A.V.; Han, R.M.; Ford, P.C. Dinitrosyl iron complexes with cysteine. Kinetics studies of the formation and reactions of DNICs in aqueous solution. J. Am. Chem. Soc. 2015, 137, 328-336. [CrossRef] [PubMed]

17. Speelman, A.L.; Zhang, B.; Silakovi, A.; Skodje, K.M.; Alp, E.E.; Zhao, J.; Hu, M.Y.; Kim, E.; Krebs, C.; Lehnert, N. Unusual Synthetic Pathway for an $\left\{\mathrm{Fe}(\mathrm{NO})_{2}\right\}^{9}$ Dinitrosyl Iron Complex (DNIC) and Insight into DNIC Electronic Structure via Nuclear Resonance Vibrational Spectroscopy. Inorg. Chem. 2016, 55, 5485-5501. [CrossRef]

18. Truzzi, D.R.; Medeiros, N.M.; Augusto, O.; Ford, P.C. Dinitrosyl Iron Complexes (DNICs). From Spontaneous Assembly to Biological Roles. Inorg. Chem. 2021, 60. in press.

19. Arnold, W.P.; Mittal, C.K.; Katsuki, S.; Murad, F. Nitric oxide activates guanylate cyclase and increases guanosine $3^{\prime}: 5^{\prime}$-cyclic monophosphate levels in various tissue preparations. Proc. Natl. Acad. Sci. USA 1977, 74, 3203-3207. [CrossRef] [PubMed]

20. Ignarro, L.J.; Byrns, R.E.; Wood, K.S. Endothelium-dependent modulation of cGMP levels and intrinsic smooth muscle tone in isolated bovine intrapulmonary artery and vein. Circ. Res. 1987, 60, 82-92. [CrossRef]

21. Vanin, A.F. Dinitrosyl iron complexes with thiol-containing ligands as a "working form" of endogenous nitric oxide. Nitric Oxide 2016, 54, 15-29. [CrossRef] [PubMed]

22. Vanin, A.F. Dinitrosyl Iron Complexes As a "Working Form" of Nitric Oxide in Living Organisms; Cambridge Scholars Publishing: Newcastle, UK, 2019; p. 279.

23. Lu, T.-T.; Wang, Y.-M.; Hung, C.-H.; Chiou, S.-J.; Liaw, W.-F. Bioinorganic Chemistry of the Natural [Fe(NO) 2 ] Motif: Evolution of a Functional Model for NO-Related Biomedical Application and Revolutionary Development of a Translational Model. Inorg. Chem. 2018, 57, 12425-12443. [CrossRef]

24. Hsiao, H.-Y.; Chung, C.-W.; Santos, J.H.; Villaflores, O.B.; Lu, T.-T. Fe in biosynthesis, translocation, and signal transduction of NO: Toward bioinorganic engineering of dinitrosyl iron complexes into NO-delivery scaffolds for tissue engineering. Dalton Trans. 2019, 48, 9431-9453. [CrossRef] [PubMed]

25. Huang, H.-W.; Lin, Y.-H.; Lin, M.-H.; Huang, Y.-R.; Chou, C.-H.; Hong, H.-C.; Wang, M.-R.; Tseng, Y.-T.; Liao, P.-C.; Chung, M.-C.; et al. Extension of C. elegans lifespan using the center dot NO-delivery dinitrosyl iron complexes. J. Biol. Inorg. Chem. 2018, 23, 775-784. [CrossRef] [PubMed]

26. Skodje, K.M.; Kwon, M.-Y.; Chung, S.W.; Kim, E. Coordination-triggered NO release from a dinitrosyl iron complex leads to anti-inflammatory activity. Chem. Sci. 2014, 5, 2374-2378. [CrossRef] 
27. Pectol, D.C.; DeLaney, C.R.; Zhu, J.; Mellott, D.M.; Katzfuss, A.; Taylor, Z.W.; Meek, T.D.; Darensbourg, M.Y. Dinitrosyl iron complexes (DNICs) as inhibitors of the SARS-CoV-2 main protease. Chem. Commun. 2021, 57, 8352-8355. [CrossRef]

28. Wu, S.-C.; Lu, C.-Y.; Chen, Y.-L.; Lo, F.-C.; Wang, T.-Y.; Chen, Y.-J.; Yuan, S.-S.; Liaw, W.-F.; Wang, Y.-M. Water-Soluble Dinitrosyl Iron Complex (DNIC): A Nitric Oxide Vehicle Triggering Cancer Cell Death via Apoptosis. Inorg. Chem. 2016, 55, 9383-9392. [CrossRef]

29. Sung, Y.-C.; Jin, P.-R.; Chu, L.-A.; Hsu, F.-F.; Wang, M.-R.; Chang, C.-C.; Chiou, S.-J.; Qiu, J.T.; Gao, D.-Y.; Lin, C.-C.; et al. Delivery of nitric oxide with a nanocarrier promotes tumour vessel normalization and potentiates anti-cancer therapies. Nat. Nanotechnol. 2019, 14, 1160-1169. [CrossRef]

30. Chazov, E.I.; Rodnenkov, O.V.; Zorin, A.V.; Lakomkin, V.L.; Gramovich, V.V.; Vyborov, O.N.; Dragnev, A.G.; Timoshin, C.A.; Buryachkovskaya, L.I.; Abramov, A.A.; et al. Hypotensive effect of Oxacom ${ }^{\circledR}$ containing a dinitrosyl iron complex with glutathione: Animal studies and clinical trials on healthy volunteers. Nitric Oxide 2012, 26, 148-156. [CrossRef]

31. Gosteev, A.; Zorin, A.V.; Rodnenkov, O.V.; Dragnev, A.G.; Chazov, E.I. Hemodynamic effects of the synthetic analogue of endogenous nitric oxide (II) donors a dinitrosyl iron complex in hypertensive patients with uncomplicated hypertensive crisis. Ter. Arkh. 2014, 86, 49-55. [PubMed]

32. Chen, Y.-J.; Wu, S.-C.; Wang, H.-C.; Wu, T.-H.; Yuan, S.-F.; Lu, T.-T.; Liaw, W.-F.; Wang, Y.-M. Activation of Angiogenesis and Wound Healing in Diabetic Mice Using NO-Delivery Dinitrosyl Iron Complexes. Mol. Pharm. 2019, 16, 4241-4251. [CrossRef]

33. Andreyev-Andriyevsky, A.A.; Mikoyan, V.D.; Serezhenkov, V.A.; Vanin, A.F. Penile erectile activity of dinitrosyl iron complexes with thiol-containing ligands. Nitric Oxide 2011, 24, 217-223. [CrossRef] [PubMed]

34. Wu, C.-R.; Huang, Y.-D.; Hong, Y.-H.; Liu, Y.-H.; Narwane, M.; Chang, Y.-H.; Dinh, T.K.; Hsieh, H.-T.; Hseuh, Y.-J.; Wu, P.-C.; et al. Endogenous Conjugation of Biomimetic Dinitrosyl Iron Complex with Protein Vehicles for Oral Delivery of Nitric Oxide to Brain and Activation of Hippocampal Neurogenesis. JACS Au 2021, 1, 998-1013. [CrossRef] [PubMed]

35. Yu, C.-C.; Chang, F.-C.; Hong, Y.-H.; Li, J.-C.; Chen, P.-L.; Chen, C.-H.; Chiu, T.-W.; Lu, T.-T.; Wang, Y.-M.; Kao, C.-F. Assessing the cognitive status of Drosophila by the value-based feeding decision. NPJ Aging Mech. Disease 2021, 7, ASAP. [CrossRef]

36. Cho, S.-L.; Liao, C.-J.; Lu, T.-T. Synthetic methodology for preparation of dinitrosyl iron complexes. J. Biol. Inorg. Chem. 2019, 24, 495-515. [CrossRef] [PubMed]

37. Lee, H.M.; Chiou, S.J. trans-Bis( $\mu$-2-hydroxy-ethanethiol-ato- $\left.\kappa^{2} S: S\right)$ bis-[dinitro-syliron(II)](Fe-Fe). Acta Cryst. E 2009, 65, m1600. [CrossRef]

38. Shmatko, N.Y.; Korchagin, D.V.; Shilov, G.V.; Sanina, N.A.; Aldoshin, S.M. Molecular and Crystal Structure of a Cationic Dinitrosyl Iron Complex with 1,3-Dimethylthiourea. J. Struct. Chem. 2017, 58, 353-355. [CrossRef]

39. Pulukkody, R.; Chupik, R.B.; Montalvo, S.K.; Khan, S.; Bhuvanesh, N.; Lim, S.M.; Darensbourg, M.Y. Toward biocompatible dinitrosyl iron complexes: Sugar-appended thiolates. Chem. Commun. 2017, 53, 1180-1183. [CrossRef]

40. Pokidova, O.V.; Luzhkov, V.B.; Emel'yanova, N.S.; Krapivin, V.B.; Kotelnikov, A.I.; Sanina, N.A.; Aldoshin, S.M. Effect of albumin on the transformation of dinitrosyl iron complexes with thiourea ligands. Dalton Trans. 2020, 49, 12674-12685. [CrossRef]

41. Pokidova, O.V.; Kormukhina, A.Y.; Kotelnikov, A.I.; Rudneva, T.N.; Lyssenko, K.A.; Sanina, N.A. Features of the decomposition of cationic nitrosyl iron complexes with $\mathrm{N}$-ethylthiourea and penicillamine ligands in the presence of albumin. Inorg. Chim. Acta 2021, 524, 120453. [CrossRef]

42. Pectol, D.C.; Khan, S.; Elsabahy, M.; Wooley, K.L.; Lim, S.M.; Darensbourg, M.Y. Effects of Glutathione and Histidine on NO Release from a Dimeric Dinitrosyl Iron Complex (DNIC). Inorg. Chem. 2020, 59, 16998-17008. [CrossRef]

43. Pectol, D.C.; Khan, S.; Chupik, R.B.; Elsabahy, M.; Wooley, K.L.; Darensbourg, M.Y.; Lim, S.M. Toward the Optimization of Dinitrosyl Iron Complexes as Therapeutics for Smooth Muscle Cells. Mol. Pharm. 2019, 16, 3178-3187. [CrossRef]

44. Watts, R.N.; Richardson, D.R. Nitrogen monoxide (no) and glucose: Unexpected links between energy metabolism and nomediated iron mobilization from cells. J. Biol. Chem. 2001, 276, 4724-4732. [CrossRef]

45. Watts, R.N.; Hawkins, C.; Ponka, P.; Richardson, D.R. Nitrogen monoxide (NO)-mediated iron release from cells is linked to NO-induced glutathione efflux via multidrug resistance-associated protein 1. Proc. Natl. Acad. Sci. USA 2006, 103, 7670-7675. [CrossRef] [PubMed]

46. Lok, H.C.; Suryo Rahmanto, Y.; Hawkins, C.L.; Kalinowski, D.S.; Morrow, C.S.; Townsend, A.J.; Ponka, P.; Richardson, D.R. Nitric oxide storage and transport in cells are mediated by glutathione S-transferase P1-1 and multidrug resistance protein 1 via dinitrosyl iron complexes. J. Biol. Chem. 2012, 287, 607-618. [CrossRef]

47. Luo, J.D.; Chen, A.F. Nitric oxide: A newly discovered function on wound healing. Acta Pharmacol. Sin. 2005, 26, 259-264. [CrossRef] [PubMed]

48. Witte, M.B.; Thornton, F.J.; Efron, D.T.; Barbul, A. Enhancement of fibroblast collagen synthesis by nitric oxide. Nitric Oxide 2000, 4, 572-582. [CrossRef] [PubMed]

49. Schwentker, A.; Billiar, T.R. Inducible nitric oxide synthase: From cloning to therapeutic applications. World J. Surg. 2002, 26, 772-778. [CrossRef] [PubMed]

50. Zhang, P.; Li, Y.; Tang, Y.; Shen, H.; Li, J.; Yi, Z.; Ke, Q.; Xu, H. Copper-Based Metal-Organic Framework as a Controllable Nitric Oxide-Releasing Vehicle for Enhanced Diabetic Wound Healing. ACS Appl. Mater. Interfaces 2020, 12, 18319-18331. [CrossRef]

51. Tung, C.Y.; Tseng, Y.T.; Lu, T.T.; Liaw, W.F. Insight into the Electronic Structure of Biomimetic Dinitrosyliron Complexes (DNICs): Toward the Syntheses of Amido-Bridging Dinuclear DNICs. Inorg. Chem. 2021, 60. in press. 
52. Cesareo, E.; Parker, L.J.; Pedersen, J.Z.; Nuccetelli, M.; Mazzetti, A.P.; Pastore, A.; Federici, G.; Caccuri, A.M.; Ricci, G.; Adams, J.J.; et al. Nitrosylation of human glutathione transferase P1-1 with dinitrosyl diglutathionyl iron complex in vitro and in vivo. J. Biol. Chem. 2005, 280, 42172-42180. [CrossRef] [PubMed]

53. Tsou, C.-C.; Lu, T.-T.; Liaw, W.-F. EPR, UV-Vis, IR, and X-ray demonstration of the anionic dimeric dinitrosyl iron complex $\left[(\mathrm{NO})_{2} \mathrm{Fe}\left(\mu-\mathrm{S}^{t} \mathrm{Bu}\right)_{2} \mathrm{Fe}(\mathrm{NO})_{2}\right]^{-}$: Relevance to the products of nitrosylation of cytosolic and mitochondrial aconitases, and highpotential iron proteins. J. Am. Chem. Soc. 2007, 129, 12626-12627. [CrossRef] [PubMed]

54. Boese, M.; Mordvintcev, P.I.; Vanin, A.F.; Busse, R.; Mulsch, A. S-nitrosation of serum albumin by dinitrosyl-iron complex. J. Biol. Chem. 1995, 270, 29244-29249. [CrossRef] [PubMed]

55. Han, G.; Nguyen, L.N.; Macherla, C.; Chi, Y.; Friedman, J.M.; Nosanchuk, J.D.; Martinez, L.R. Nitric oxide-releasing nanoparticles accelerate wound healing by promoting fibroblast migration and collagen deposition. Am. J. Pathol. 2012, 180, 1465-1473. [CrossRef] [PubMed]

56. Krischel, V.; Bruch-Gerharz, D.; Suschek, C.; Kroncke, K.D.; Ruzicka, T.; Kolb-Bachofen, V. Biphasic effect of exogenous nitric oxide on proliferation and differentiation in skin derived keratinocytes but not fibroblasts. J. Investig. Dermatol. 1998, 111, $286-291$. [CrossRef] [PubMed]

57. Gurtner, G.C.; Werner, S.; Barrandon, Y.; Longaker, M.T. Wound repair and regeneration. Nature 2008, 453, 314-321. [CrossRef]

58. Frank, S.; Kampfer, H.; Wetzler, C.; Pfeilschifter, J. Nitric oxide drives skin repair: Novel functions of an established mediator. Kidney Int. 2002, 61, 882-888. [CrossRef]

59. Choi, Y.J.; Uehara, Y.; Park, J.Y.; Chung, K.W.; Ha, Y.M.; Kim, J.M.; Song, Y.M.; Chun, P.; Park, J.W.; Moon, H.R.; et al. Suppression of melanogenesis by a newly synthesized compound, MHY966 via the nitric oxide/protein kinase G signaling pathway in murine skin. J. Dermatol. Sci. 2012, 68, 164-171. [CrossRef]

60. Horikoshi, T.; Nakahara, M.; Kaminaga, H.; Sasaki, M.; Uchiwa, H.; Miyachi, Y. Involvement of nitric oxide in UVB-induced pigmentation in guinea pig skin. Pigment Cell Res. 2000, 13, 358-363. [CrossRef]

61. Beekhuijzen, M.; de Koning, C.; Flores-Guillen, M.E.; de Vries-Buitenweg, S.; Tobor-Kaplon, M.; van de Waart, B.; Emmen, H. From cutting edge to guideline: A first step in harmonization of the zebrafish embryotoxicity test (ZET) by describing the most optimal test conditions and morphology scoring system. Reprod. Toxicol. 2015, 56, 64-76. [CrossRef]

62. Li, J.; Jia, W.; Zhao, Q. Excessive nitrite affects zebrafish valvulogenesis through yielding too much NO signaling. PLoS ONE 2014, 9, e92728. [CrossRef] [PubMed]

63. Hsu, T.W.; Lu, Y.J.; Lin, Y.J.; Huang, Y.T.; Hsieh, L.H.; Wu, B.H.; Lin, Y.C.; Chen, L.C.; Wang, H.W.; Chuang, J.C.; et al. Transplantation of 3D MSC/HUVEC spheroids with neuroprotective and proangiogenic potentials ameliorates ischemic stroke brain injury. Biomaterials 2021, 272, 120765. [CrossRef] [PubMed]

64. Li, P.-C.; Chen, S.-C.; Hsueh, Y.-J.; Shen, Y.-C.; Tsai, M.-Y.; Hsu, L.-W.; Yeh, C.-K.; Chen, H.-C.; Huang, C.-C. Gelatin scaffold with multifunctional curcumin-loaded lipid-PLGA hybrid microparticles for regenerating corneal endothelium. Mater. Sci. Eng. C Mater. Biol. Appl. 2021, 120, 111753. [CrossRef] [PubMed]

65. Shang, Q.; Chu, Y.; Li, Y.; Han, Y.; Yu, D.; Liu, R.; Zheng, Z.; Song, L.; Fang, J.; Li, X.; et al. Adipose-derived mesenchymal stromal cells promote corneal wound healing by accelerating the clearance of neutrophils in cornea. Cell Death Dis. 2020, 11, 707. [CrossRef] [PubMed]

66. Seo, G.Y.; Ha, Y.; Park, A.H.; Kwon, O.W.; Kim, Y.J. Leathesia difformis Extract Inhibits alpha-MSH-Induced Melanogenesis in B16F10 Cells via Down-Regulation of CREB Signaling Pathway. Int. J. Mol. Sci. 2019, 20, 536. [CrossRef] [PubMed]

67. Oh, T.I.; Jung, H.J.; Lee, Y.M.; Lee, S.; Kim, G.H.; Kan, S.Y.; Kang, H.; Oh, T.; Ko, H.M.; Kwak, K.C.; et al. Zerumbone, a Tropical Ginger Sesquiterpene of Zingiber officinale Roscoe, Attenuates alpha-MSH-Induced Melanogenesis in B16F10 Cells. Int. J. Mol. Sci. 2018, 19, 3149. [CrossRef] [PubMed]

68. Chung, Y.C.; Ko, J.H.; Kang, H.K.; Kim, S.; Kang, C.I.; Lee, J.N.; Park, S.M.; Hyun, C.G. Antimelanogenic Effects of Polygonum tinctorium Flower Extract from Traditional Jeju Fermentation via Upregulation of Extracellular Signal-Regulated Kinase and Protein Kinase B Activation. Int. J. Mol. Sci. 2018, 19, 2895. [CrossRef]

69. Chiang, C.E.; Fang, Y.Q.; Ho, C.T.; Assuncao, M.; Lin, S.J.; Wang, Y.C.; Blocki, A.; Huang, C.C. Bioactive Decellularized Extracellular Matrix Derived from 3D Stem Cell Spheroids under Macromolecular Crowding Serves as a Scaffold for Tissue Engineering. Adv. Healthc. Mater. 2021, 10, e2100024. [CrossRef]

70. Chatatikun, M.; Yamauchi, T.; Yamasaki, K.; Aiba, S.; Chiabchalard, A. Anti melanogenic effect of Croton roxburghii and Croton sublyratus leaves in alpha-MSH stimulated B16F10cells. J. Tradit. Complement. Med. 2019, 9, 66-72. [CrossRef]

71. OECD. Test No. 439: In Vitro Skin Irritation: Reconstructed Human Epidermis Test Method; OECD Publishing: Paris, France, 2010. [CrossRef]

72. OECD. Test No. 492: "Reconstructed Human Cornea-Like Epithelium (RhCE) Test Method for Identifying Chemicals Not Requiring Classification and Labeling for Eye Irritation or Serious Eye Damage"; OECD Publishing: Paris, France, 2019. [CrossRef]

73. Lanham, K.A.; Prasch, A.L.; Weina, K.M.; Peterson, R.E.; Heideman, W. A dominant negative zebrafish Ahr2 partially protects developing zebrafish from dioxin toxicity. PLOS ONE 2011, 6, e28020. [CrossRef]

74. Manjunatha, B.; Han, L.; Kundapur, R.R.; Liu, K.; Lee, S.J. Herbul black henna (hair dye) causes cardiovascular defects in zebrafish (Danio rerio) embryo model. Environ. Sci. Pollut. Res. Int. 2020, 27, 14150-14159. [CrossRef] 